Estudios Constitucionales, Año 17, № 2, 2019, pp. 225-264

ISSN 07180195

Centro de Estudios Constitucionales de Chile Universidad de Talca

"El Protocolo facultativo de la Convención sobre los Derechos del Niño relativo

a un procedimiento de comunicaciones. Estudio a la luz de su aplicabilidad"

Isaac Ravetllat Ballesté - Cristian Contreras Rojas

\title{
EL PROTOCOLO FACULTATIVO DE LA CONVENCIÓN SOBRE LOS DERECHOS DEL NIÑO RELATIVO A UN PROCEDIMIENTO DE COMUNICACIONES. ESTUDIO A LA LUZ DE SU APLICABILIDAD
}

Optional Protocol to the Convention on the Rights of the Child on a COMMUNications PROCEDURe. STUdy IN THE LIGHT OF ITS APPLICABILITY

\author{
IsAac RAVETLlat BaLlesté* \\ Universidad de Talca \\ iravetllat@utalca.cl \\ Cristian Contreras Rojas** \\ Universidad de Talca \\ ccontreras@utalca.cl
}

RESUMEN: Adoptado por la Asamblea General de las Naciones Unidas el 19 de diciembre de 2011 -A/RES/66/138-, el tercer Protocolo facultativo de la Convención sobre los Derechos del Niño instaura un procedimiento de comunicaciones en virtud del cual los particulares-incluidos niños, niñas y adolescentes- pueden dirigirse ante el Comité de los Derechos del Niño alegando presuntas vulneraciones de los derechos contenidos tanto en la Convención como en sus dos Protocolos facultativos sustantivos del año 2000.

Ante un panorama como el descrito, el planteamiento de nuestro estudio se centra en un análisis pormenorizado de las nuevas competencias atribuidas al Comité de los Derechos del Niño a tenor del mentado tercer Protocolo facultativo. Efectivamente, al dotar al Comité de una facultad cuasijurisdiccional, al reconocérsele la posibilidad de recibir y resolver quejas individuales presentadas por sujetos o grupos de sujetos, muta, en cierta medida, la conceptualización tradicional que hasta

\footnotetext{
* Profesor Asistente de la Facultad de Ciencias Jurídicas y Sociales de la Universidad de Talca. Doctor y Magíster en Derecho de Familia e Infancia por la Universidad de Barcelona (España). Director del Centro de Estudios sobre los Derechos de la Infancia y la Adolescencia de la Universidad de Talca. Vocal del Observatorio de la Infancia de la Generalitat de Cataluña (España). Secretario General de la Asociación para la Defensa de los Derechos de la Infancia y la Adolescencia (ADDIA).

** Profesor Asistente de la Facultad de Ciencias Jurídicas y Sociales de la Universidad de Talca. Doctor en Derecho por la Universidad de Barcelona (España).
}

Artículo recibido el 6 de agosto de 2019 y aprobado el 6 de noviembre de 2019. 
el momento se venía manteniendo del citado órgano ginebrino y de sus formas de intervención e incidencia social.

ABSTRACT: The General Assembly of the United Nations adopted on December 19, 2011 -A/ RES/66/138-, the Optional Protocol to the Convention on the Rights of the Child on a communications procedure under which individuals-including children and adolescents - can be addressed to the Committee on the Rights of the Child, indicating the existence of alleged violations of the rights contained in both the Convention and its two substantive Optional Protocols of the year 2000.

Given the described situation, the approach of our study focuses on a detailed analysis of the new competences attributed to the Committee on the Rights of the Child in the light of the third Optional Protocol. Indeed, by giving the Committee a quasi-jurisdictional faculty, by recognizing the possibility of receiving and resolving individual complaints presented by subjects or groups of subjects, it mutates, to a certain extent, the traditional conceptualization that until now it has been maintained about the genevan organ and its forms of intervention and social impact.

PalABRAS CLAVE: Comité de los derechos del niño; derechos humanos de niños, niñas y adolescentes; procedimiento de comunicaciones; Convención sobre los Derechos del Niño; comunicaciones individuales; comunicaciones interestatales.

KEY WORDS: Committee on the Rights of the Child; human rights of children and adolescents; communications procedure; individual communications, interstate communications.

\section{INTRODUCCIÓN}

El 14 de abril de 2014, tres meses después del depósito en poder del Secretario General de las Naciones Unidas del décimo instrumento de manifestación de voluntad requerido - umbral mínimo que se logró con la ratificación de Costa Rica-, entró en vigor de forma general el Protocolo facultativo de la Convención sobre los Derechos del Niño relativo a un procedimiento de comunicaciones (en adelante, Protocolo o Protocolo facultativo).

Adoptado por la Asamblea General el 19 de diciembre de 2011 -A/RES/66/138-, este Protocolo instaura un procedimiento de comunicaciones individuales en virtud del cual personas o grupos de personas que se hallen bajo la jurisdicción de un Estado Parte y que aleguen ser víctimas de una violación por ese Estado de cualquiera de los derechos enunciados en la Convención sobre los Derechos del Niño y/o en sus dos Protocolos facultativos sustantivos ${ }^{1}$, puedan instar al Comité de los Derechos del Niño para que emita un dictamen y realice recomendaciones acerca de la violación denunciada. Asimismo,

\footnotetext{
1 Se trata del Protocolo facultativo de la Convención sobre los Derechos del Niño relativo a la venta de niños, la prostitución infantil y la utilización de niños en la pornografía y del Protocolo facultativo de la Convención sobre los Derechos del Niño relativo a la participación de niños en los conflictos armados, ambos adoptados por la Asamblea General el 25 de mayo de 2000 (A/RES/54/263).
} 
también se prevé la posibilidad de que el requerimiento sea presentado por un Estado que alegue el incumplimiento de otro -comunicaciones interestatales-, o incluso que el procedimiento se inicie de oficio por el propio Comité, sin que se requiera una comunicación, cuando este órgano ha tomado conocimiento de evidencias fehacientes de violaciones graves o sistemáticas de los derechos de la niñez.

Como se aprecia, la intervención del Comité podrá generarse de oficio o a instancia de una o más personas o de Estados, empero, esto va a depender de las declaraciones particulares que realicen los Estados al momento de ratificar o adherir al Protocolo. De esta forma, resulta de la esencia la posibilidad de que una o más personas puedan realizar comunicaciones al Comité, bastando para ello con que el Estado adquiera el carácter de parte de este instrumento internacional, no pudiendo realizar ninguna declaración que modifique o altere esta forma de inicio del procedimiento ${ }^{2}$. Sin embargo, tratándose de las comunicaciones entre Estados, ellas se hacen depender de una cláusula de inclusión -opting o contracting in ${ }^{3}-$, de modo que se requiere un reconocimiento expreso de la competencia de la Comisión en este sentido (art. 12.1). A su turno, para el procedimiento de investigación de oficio en supuestos de violaciones graves o sistemáticas ${ }^{4}$, se ha establecido una cláusula de exclusión -opting o contracting out-, por lo que se permite al Estado no reconocer esta competencia al Comité (art. 13.7).

La entrada en vigor de este Protocolo constituye, en definitiva, un verdadero hito en la historia del sistema universal de protección de los Derechos Humanos,

\footnotetext{
2 En lo tocante a las reservas este Protocolo facultativo fía al régimen flexible de la Convención de Viena sobre el Derecho de los Tratados (1969) la prohibición de formular reservas incompatibles con su objeto y $\sin$ (artículo 19.c).

3 La interpretación ofrecida por el Comité de los Derechos del Niño al redactado del art. 12.1 del Protocolo, es proclive a permitir a los Estados partes formular tal declaración de voluntad respecto de todos o solo alguno de los instrumentos bajo su supervisión: la Convención y los dos Protocolos facultativos sustantivos de 2000. Lo anterior se extrae de https://www.ohchr.org/EN/HRBodies/TBPetitions/Pages/ HRTBPetitions.aspx\#interstate [fecha de consulta: 29 de julio de 2919].

4 El Comité de los Derechos del Niño hubiera preferido utilizar la expresión "violaciones graves o repetidas" en lugar de referirse a "violaciones graves o sistemáticas". El órgano ginebrino encuentra que el adjetivo "sistemáticas" es demasiado restrictivo, ya que del mismo se desprende que el Estado ejerce una política deliberada de violación de los derechos del niño. Además, defendió la necesidad de añadir en el Protocolo facultativo una disposición en la que se indicara que corresponde al Comité la competencia de elaborar unas normas que contengan los criterios con los que definir qué se consideran "violaciones" o "repetidas". Asamblea General de las Naciones Unidas (2010a), párrafo 21.
} 
pues, a partir de este preciso instante, todos los tratados de derechos humanos de Naciones Unidas dotados de órganos propios de supervisión, sin excepción alguna, cuentan ya con un mecanismo directo de denuncia de vulneraciones de su articulado5.

Otro elemento digno de ser tomado en consideración, radica en la circunstancia de que a pesar de que los Protocolos facultativos fueron inicialmente concebidos en las Naciones Unidas pensando única y exclusivamente en los derecho civiles y políticos - derechos de primera generación-, hoy en día tal afirmación debe ser puesta en entredicho, al extenderse sus competencias a los derechos económicos, sociales y culturales -derechos de segunda generación-. Muestra de ello es que, además del mencionado tercer Protocolo, también se ha aprobado y entrado en vigor el Protocolo facultativo del Pacto Internacional de Derechos Económicos, Sociales y Culturales ${ }^{6}$. Este, por su evidente adscripción a esta tipología de derechos, y aquel, por partir de un enfoque omnicomprensivo que considera que todos y cada uno de los Derechos Humanos contenidos en el articulado de la Convención de 1989 son indivisibles e interdependientes entre sí, de manera que no es posible establecer diferencias entre ellos atendido su contenido específico o la generación a que pertenecen.

No obstante lo apuntado ut supra, un dato preocupante, y que debiera llevarnos a la reflexión, tiene relación con el reducido número de ratificaciones que ha obtenido el tercer Protocolo facultativo. En efecto, solo cuenta con 44, frente a las 168 del Protocolo facultativo sobre la participación de niños en los conflictos armados y las 175 del relativo a la venta de niños, la prostitución infantil y la utilización de niños en la pornografía. Es más, de esos 44 Estados,

5 En palabras de CARDONa (2012), p. 65, con este Protocolo facultativo "los niños dejan de ser mini-personas con mini-derechos, para ser definitivamente personas con derechos plenos que pueden hacer valer no sólo en el ámbito interno sino también en el internacional". Por su parte, de acuerdo con CARMONA (2011), p. 143, la doctrina y jurisprudencia derivada de este mecanismo especializado debe contribuir significativamente a la interpretación de la Convención, así como beneficiar a los mecanismos y órganos nacionales, regionales e internacionales.

6 Para Riquelme (2014), p. 12, un elemento a resaltar de la entrada en vigor de este Protocolo radica en el hecho que, al igual que ocurriera con la entrada en vigor del Protocolo facultativo del Pacto Internacional de Derechos Económicos, Sociales y Culturales, de 10 de diciembre de 2008, el procedimiento se extiende por vez primera a los derechos económicos, sociales y culturales, tradicionalmente considerados de segunda generación por imponer no obligaciones de resultado como las derivadas de los derechos civiles y políticos, sino meras obligaciones de comportamiento progresivo supeditadas a la disponibilidad de recursos y a la política económica y social estatal. En un sentido similar se pronuncia SAURA (2013), pp. 53-80. Por último, también pone de relieve esta circunstancia BECO (2013), p. 368. 
únicamente 12 han reconocido de manera expresa la competencia del Comité de los Derechos del Niño para conocer comunicaciones entre Estados ${ }^{7}$. Sin lugar a dudas, estas cifras denotan el escaso interés que ha suscitado entre los Estados, al menos por el momento, la posibilidad de atribuir un carácter cuasijurisdiccional al órgano de supervisión de la Convención sobre los Derechos del Niño8.

Teniendo lo anterior como telón de fondo, el presente artículo aborda el análisis pormenorizado de las principales características que identifican al Protocolo facultativo de la Convención sobre los Derechos del Niño relativo a un procedimiento de comunicaciones. En primer término, nos referiremos a los orígenes del mentado texto internacional, así como al estudio de su proceso de implantación y desarrollo. Una vez efectuada esta declaración general de intenciones, profundizaremos en el iter procedimental que deben seguir las llamadas comunicaciones individuales: quién ostenta legitimación activa para su presentación; en qué consisten las medidas de protección y provisionales que pueden ser adoptadas por el Comité de los Derechos del Niño; cuáles son las causales de inadmisibilidad previstas en el propio Protocolo; y en qué se concreta el resultado final de este procedimiento cuasi-jurisdiccional, son solo algunas de las interrogantes a las que trataremos de dar debida respuesta. Acto seguido, haremos mención al mecanismo de reclamación interestatal previsto. En particular, indagaremos en los motivos que provocan que este recurso no sea particularmente atractivo para los Estados, lo que se traduce en una infrautilización del mismo. Por último, relataremos la manera cómo el Comité de los Derechos del Niño puede actuar de oficio en caso de violaciones graves o sistemáticas contra los derechos de la niñez por actos u omisiones de un Estado parte.

\footnotetext{
7 A saber: Albania, Bélgica. Chile, República Checa, Finlandia, Alemania, Italia, Liechtenstein, Portugal, Eslovaquia, Eslovenia y Suiza. Para una información actualizada al respecto, consultar la página web oficial de las Naciones Unidas, concretamente https://treaties.un.org/Pages/ViewDetails.aspx?src=TREATY\&mtdsg_ no=IV-11-d\&chapter=4\&clang=_en [fecha de consulta: 30 de julio de 2019].

8 Siguiendo esta misma lógica, SMITH (2010), p. 229, se hace eco de la escasa utilización histórica de este tipo de mecanismos cuasi-jurisdiccionales en el seno de las Naciones Unidas. Una pequeña luz de esperanza se atisba en el horizonte al comprobar que durante los últimos años ha habido una tendencia al alza con respecto al número de comunicaciones presentadas ante el Comité de los Derechos del Niño. Para ser más exactos, de las 32 comunicaciones que han sido aceptadas a trámite desde el mes de abril de 2014, 27 lo fueron durante el año 2017, lo cual denota un ligero cambio de tendencia.
} 


\section{Origen del tercer Protocolo facultativo de la Convención SOBRe los Derechos DEL NiÑo}

Para conocer el verdadero origen de estos mecanismos cuasi jurisdiccionales que habilitan a cada uno de los órganos colegiados previstos en las diferentes Convenciones sobre Derechos Humanos de las Naciones Unidas ${ }^{9}$-en nuestro caso el Comité de los Derechos del Niño- a admitir y analizar comunicaciones individuales, debemos remontarnos a los primeros años de vida de la Organización de las Naciones Unidas. Así, la Carta de las Naciones Unidas había consagrado la obligación de los Estados de respetar y garantizar los Derechos Humanos, lo que despertó grandes esperanzas en la ciudadanía y motivó el envío de una gran cantidad de comunicaciones a la sede de las Naciones Unidas, en las que denunciaban violaciones de Derechos Humanos ${ }^{10}$. Tal circunstancia provocó que se planteara seriamente la duda acerca de si la Carta otorgaba a esta organización las competencias para tramitar y dar debida respuesta a estos requerimientos. Finalmente, ante tal tesitura, la Comisión de Derechos Humanos abdicó en 1947 de la posibilidad de intervenir directamente en ese tipo de cuestiones ${ }^{11}$.

En atención a lo apuntado, la posibilidad real de presentar comunicaciones individuales se reconoció por vez primera en el artículo 14 de la Convención Internacional sobre la Eliminación de todas las Formas de Discriminación Racial de $1965^{12}$. Paralelamente, también trató de incorporarse idéntica previsión en el articulado del coetáneo Pacto Internacional de Derechos Civiles y Políticos de 1966 -en adelante, PIDCP-, pero fruto de las profundas desavenencias surgidas al respecto, se optó, a iniciativa de la delegación libanesa, por desarrollar dicha posibilidad en un instrumento separado, para favorecer con ello que aquellos

\footnotetext{
9 Estos órganos son los enumerados acto seguido: el Comité de los Derechos Humanos (CDH); el Comité de Derechos Económicos, Sociales y Culturales (CDESC); el Comité contra la Tortura (CCT); el Comité para la Protección de los Derechos de todos los Trabajadores Migratorios y sus Familias (CTM); el Comité de los Derechos de las Personas con Discapacidad (CDPD); el Comité contras las Desapariciones Forzosas; el Comité para la Eliminación de la Discriminación Racial (CEDR); y el Comité para la Eliminación de la Discriminación contra la Mujer (CEDM).

10 ОСНOA (2004), p. 35.

11 En este sentido, OchOA (2004), pp. 288-292 y Carlson y Gisvold (2003), pp. 9-13.

$12 \mathrm{El}$ art. 14.1 de la Convención señala expresamente: "Todo Estado parte podrá declarar en cualquier momento que reconoce la competencia del Comité para recibir y examinar comunicaciones de personas o grupos de personas comprendidas dentro de su jurisdicción, que alegaren ser víctimas de violaciones, por parte de ese Estado, de cualquiera de los derechos estipulados en la presente Convención. El Comité no recibirá ninguna comunicación referente a un Estado parte que no hubiere hecho tal declaración".
} 
Estados que no desearan reconocer tal posibilidad no tuvieran la obligación de hacerlo. De este modo, se adoptó el Protocolo facultativo del PIDCP de 1966, que en su artículo 1 dota al Comité de Derechos Humanos de la competencia para recibir y resolver comunicaciones individuales, en forma similar a lo previsto por la Convención recién aludida ${ }^{13}$.

Fijando ahora nuestra atención en las competencias atribuidas al Comité de los Derechos del Niño, es preciso recordar que la voluntad de dotar a la Convención sobre los Derechos del Niño de un procedimiento de comunicaciones individuales, a fin de velar por la existencia de recursos jurídicos a nivel internacional, ya se suscitó durante los debates de elaboración de este tratado internacional ${ }^{14}$. Tiempo después, durante los actos de conmemoración de su $10^{\circ}$ aniversario (1999) ${ }^{15}$, se volvió a plantear nuevamente la cuestión, sin resultados destacables ${ }^{16}$. Por ello, hubo que aguardar hasta el año 2009, con ocasión de los actos de celebración del $20^{\circ}$ aniversario de la Convención, para que se dieran, entonces sí, los elementos necesarios para abordar por fin su estudio en profundidad ${ }^{17}$.

13 En efecto, esta disposición establece que: "Todo Estado Parte en el Pacto que llegue a ser parte en el presente Protocolo reconoce la competencia del Comité para recibir y considerar comunicaciones de individuos que se hallen bajo la jurisdicción de ese Estado y que aleguen ser víctimas de una violación, por ese Estado Parte, de cualquiera de los derechos enunciados en el Pacto. El Comité no recibirá ninguna comunicación que concierna a un Estado Parte en el Pacto que no sea parte en el presente Protocolo".

14 Langford y Clark (2010), p. 374.

15 No olvidar en este punto, que la Unión Africana aprobó en 1999 la Carta Africana sobre los Derechos y el Bienestar del Niño, y que este tratado internacional habilita, en su artículo 44, al Comité Africano de Expertos sobre los Derechos y el Bienestar del Niño a recibir comunicaciones individuales de denuncias relativas a violaciones de derechos contenidos en la mentada Carta. Además, en marzo de 2011, el Comité adoptó su primera resolución frente a una comunicación presentada por el Institute for Human Rights and Development in Africa -organismo con sede en la República de Gambia- y por la New York-based Open Society Justice Initiative, en representación de los niños y niñas descendientes de Nubia residentes en Kenia. El Comité llegó a la conclusión de que el Gobierno keniano había incurrido en múltiples vulneraciones de la Carta Africana sobre los Derechos y el Bienestar del Niño (artículos 6.2, 6.3, 6.4, 11.3 y 14.2) y le recomendó adoptar todas las medidas necesarias para subsanar esa situación. AfRICAN COMMITTEE ON THE Rights and Welfare of the Child (2011).

16 El Comité de los Derechos del Niño afirmó en tal ocasión que "estudiaría la posibilidad de iniciar los debates sobre un Protocolo facultativo de la Convención que la dote de un mecanismo de presentación de comunicaciones individuales, a fin de velar por la existencia de recursos jurídicos a nivel internacional'. COMITÉ de los Derechos del Niño (1999), párrafo 291 (j). En este sentido se pronuncia Beco (2013), p. 369.

17 Ver Philips (2013), p. 5. 
Efectivamente, la ratificación casi universal de la Convención y de sus dos Protocolos facultativos sustantivos del año 2000, así como el hecho de que los demás tratados básicos de Derechos Humanos ya dispusieran de un procedimiento de comunicaciones, fue lo que principalmente tomó en consideración el Consejo de Derechos Humanos para decidir crear un grupo de trabajo abierto -open-ended working group- encargado de estudiar la posibilidad de elaborar un Protocolo facultativo de la Convención sobre los Derechos del Niño relativo a un procedimiento de comunicaciones ${ }^{18}$. En su primer período de sesiones - diciembre de $2009^{19}$ - numerosos Estados y especialistas en la materia subrayaron, además, el valor añadido del procedimiento en la medida en que reforzaría la condición de los niños y las niñas como sujetos titulares de derechos y les brindaría la oportunidad de ser oídos, así como de ejercer derechos de forma autónoma, siempre tomando en consideración su edad y estado de madurez ${ }^{20}$.

El segundo período de sesiones del grupo de trabajo se estructuró en dos momentos temporales claramente diferenciados: del 6 al 10 de diciembre de 2010, y del 10 al 16 de febrero de 2011. Durante el primero de los encuentros, se llevó a cabo una relectura artículo por artículo del primer borrador de

18 Consejo de Derechos Humanos (2009). Es menester añadir que la iniciativa de aprobar un nuevo protocolo con esta finalidad surgió de un grupo reducido de Estados (Chile, Egipto, Eslovenia, Eslovaquia, Finlandia, Francia, Kenia, Maldivas, Tailandia y Uruguay), los mismos que contribuyeron a la aprobación de la citada resolución del Consejo.

19 De conformidad con la Resolución del Consejo de Derechos Humanos 11/1, de 17 de junio de 2009, se decidió que el grupo de trabajo se reuniera del 14 al 18 de diciembre de 2009. Sin embargo, habida cuenta de que la Secretaría de las Naciones Unidas no se hallaba en condiciones de proporcionar servicios de interpretación en los seis idiomas oficiales los dos primeros días, el grupo de trabajo solo pudo reunirse del 16 al 18 de diciembre de 2009. Durante este primer período de sesiones, el grupo de trabajo eligió como su Presidente-Relator al Sr. Drahoslav Stefánek (Eslovaquia). Sobre la base de una propuesta del presidente, el grupo convino en celebrar un debate general, que iría seguido de presentaciones a cargo de expertos y diálogos en torno a las siguientes cuestiones: a) las razones y el calendario para analizar un procedimiento de comunicaciones en el marco de la Convención; b) los mecanismos internacionales existentes, su eficiencia y su accesibilidad para los niños y las niñas; c) la eficiencia en la protección de los derechos del niño/a en el marco de los mecanismos existentes en los planos nacional y regional; d) la naturaleza singular de los derechos del niño/a y los consagrados en la Convención, incluido el derecho del niño/a a ser escuchado; y e) las consecuencias de la existencia de un procedimiento de comunicaciones en el marco de la Convención y la viabilidad del procedimiento. Asamblea General de las Naciones Unidas (2010d), párrafos 3, 5, 16 y 26.

20 Carmona (2011), p. 140. En este sentido, Nogueira sostiene la obligación de los Estados de respetar, asegurar, promover y garantizar el pleno goce y ejercicio de los derechos de los niños, niñas y adolescentes que se encuentren bajo su jurisdicción. NogueIra (2017), p. 416. 
Protocolo facultativo ${ }^{21} \mathrm{y}$, acto seguido, sobre la base de los debates suscitados, el presidente del grupo de trabajo preparó un texto revisado de la propuesta ${ }^{22}$. De este modo, el segundo encuentro sirvió para analizar y discutir en profundidad el contenido de ese segundo borrador del documento. Para facilitar esta labor, el presidente del grupo de trabajo dividió los preceptos del Protocolo en tres grandes bloques: uno que reunía los artículos sobre los que ya existía consenso; otro referido a aquellos sobre los que se podía alcanzar un acuerdo con simples modificaciones; y finalmente, un subgrupo con las disposiciones más controvertidas.

El texto fue redactado en un plazo relativamente breve, pues en poco más de un año desde que se iniciaran las labores del grupo de trabajo se contaba ya con un proyecto de Protocolo ${ }^{23}$. Así, el 16 de febrero de 2011 el grupo presidido por el Sr. Stefánek aprobó el referido documento y así lo transmitió al Consejo de Derechos Humanos. Poco después, mediante la Resolución No 17/18, de 17 de junio de 2011 -A/66/53-, el Consejo aprobó su contenido por consenso y lo recomendó a la Asamblea General, que el 19 de diciembre de 2011 lo adoptó sin necesidad de someterlo a votación -A/RES/66/13824_.

\section{Procedimiento de Comunicaciones individuales}

\subsection{Legitimación activa y medidas de protección}

Toda persona o grupo de personas, en nombre propio o debidamente representadas, sujetas a la jurisdicción de un Estado parte que afirmen ser víctimas de una vulneración por el mismo de una o varias disposiciones de la Convención y/o de sus Protocolos facultativos sustantivos, ostentan legitimación activa para presentar comunicaciones individuales ante el Comité de los Derechos del Niño. Siempre, por supuesto, que se reúnan los requisitos de admisibilidad recogidos en el artículo 7 del propio Protocolo.

Lo anterior se entiende sin exclusión alguna por razones de edad, no tan solo debido a que en todo momento tanto el Protocolo -artículo 5- como su

\footnotetext{
21 El primer borrador puede consultarse en Asamblea General de las Naciones Unidas (2010b). Asimismo, para un comentario detallado de este documento ver LANGFORD y Clark (2010), pp. 1-7.

22 El borrador revisado puede consultarse en Asamblea General de las Naciones Unidas (2011b).

23 Asamblea General de las Naciones Unidas (2010c).

24 Riquelme (2014), pp. 27-28.
} 
Reglamento de aplicación -artículos 12 y 13- utilizan el vocablo "persona"25, sino también por la circunstancia de que la mentada legitimación se reconoce con independencia de que el Estado parte contra el que se dirige la comunicación reconozca o no su capacidad jurídica -artículo 13.1 del Reglamento de aplicación-. Es decir, a pesar de que en la normativa doméstica del Estado demandado no se reconozca a las personas menores de edad la autonomía suficiente como para presentar por sí requerimientos ante instancias resolutivas de conflictos, el Comité atendiendo a la edad y estado de madurez del sujeto - principio de la autonomía progresiva- puede hacer caso omiso de tales limitaciones $^{26}$. En caso contrario, podría darse la paradoja de que otros mecanismos cuasi-jurisdiccionales creados en el seno de otros tratados internacionales de las Naciones Unidas en materia de Derechos Humanos fueran más accesibles a las demandas de las personas menores de edad que el propio Comité de los Derechos del Niño 27.

Asimismo, también pueden presentar comunicaciones los representantes legales u otras personas que actúen en nombre de la presunta o presuntas víctimas con su consentimiento expreso. En este sentido, corresponde al Comité, siempre que existan dudas fundadas, la responsabilidad de indagar sobre si ese consentimiento se ha obtenido o no mediante presiones o incitaciones indebidas y si repercute efectivamente, en el interés superior del niño.

Cabe, además, presentar comunicaciones en nombre de la presunta o presuntas víctimas sin contar con tal consentimiento expreso, siempre que el autor o los autores ${ }^{28}$ de la comunicación puedan justificar sus actos y el Comité considere que la comunicación responde al interés superior del niño. En estos casos, cuando ello sea posible, la presunta o presuntas víctimas en cuyo nombre se actúa deben ser informadas, al igual que debe tomarse en consideración su

25 Durante el segundo período de sesiones del grupo de trabajo abierto encargado de elaborar un borrador de Protocolo facultativo, se consideró que el derecho a presentar una comunicación debía adjudicarse a "personas o grupos de personas", por ser este un concepto más amplio que el de "niños o grupos de niños". Asamblea General de las Naciones Unidas (2011a), párrafo 38.

26 Maravall (2019), pp. 13-17.

27 El propio Tribunal Europeo de Derechos Humanos ha reconocido legitimación activa a las personas menores de edad en aquellos casos en que existe un conflicto de intereses entre el niño o la niña y su representante legal. En este sentido, el caso $A v$. United Kingdom, de 23 de septiembre de 1998.

28 De acuerdo con el artículo 12 del Reglamento se entiende por autor o autores de una comunicación individual a "la persona o las personas que presentan la comunicación individual, sean o no la presunta o las presuntas victimas". 
opinión, en consonancia con su edad y estado de madurez. Este supuesto sería procedente en situaciones en los que el autor de la comunicación no tenga acceso a la víctima a fin de obtener su consentimiento, o bien, teniéndolo, ella se encuentre imposibilitada de prestarlo válidamente, como sería en el caso de personas menores de edad afectadas por una situación de discapacidad o de edades muy tempranas, de modo que no sean capaces de comprender cabalmente la representación que hará de ellos, su objetivo o finalidad.

De conformidad con este último punto, indicar que el Protocolo dota de cobertura a la posibilidad, ciertamente habitual en la práctica, de que grupos de niños, niñas y adolescentes en situación de particular vulnerabilidad sean asesorados y representados por entidades de la sociedad civil -ONGs-. Ante tal circunstancia, el Comité de los Derechos del Niño debe admitir este tipo de comunicaciones siempre y cuando se desprenda que son presentadas en nombre del o los afectados ${ }^{29}$. Por el contrario, no deben prosperar los escritos de queja interpuestos por entidades privadas sin ánimo de lucro que aleguen, sin más, tener un "interés suficiente" en una cuestión, ya que con ello se corre el riesgo de llegar a admitir denuncias meramente especulativas, vale decir, a través de las cuales se pretenda instar modificaciones normativas o políticas públicas en abstracto $^{30}$.

En suma, si se interviene defendiendo los intereses de un grupo de personas -menores de edad-, se requiere que estas estén directa y personalmente afectadas por la supuesta vulneración de la Convención y/o Protocolos facultativos sustantivos, cerrándose así la puerta a una suerte de actio popularis ${ }^{31}$ contra la

29 Buena muestra de ello serían las comunicaciones presentadas contra el Estado español por el trato irrogado al colectivo de adolescentes migrantes en situación irregular y sin referentes familiares a los que, según las comunicaciones presentadas, se les deniega de forma sistemática su derecho migratorio. Ver en este sentido las Comunicaciones No 39/2017, de 31 de mayo de 2018 -CRC/C/78/D/39/2017-; No 18/2017, de 25 de enero de 2018 -CRC/C/77/D/18/2017-; No 9/2017, de 2 de junio de 2017 -CRC/C/75/D/9/2017-; No 8/2016, de 31 de mayo de 2018 -CRC/C/78/D/8/2016-; y No 1/2014, de 4 de junio de 2015 -CRC/C/69/D/1/2014-.

30 BECO (2013), p. 375.

31 Hasta el caso Nicholas Toonen v. Australia, Comunicación No 488/1992, de 4 de abril de 1994 -CCPR/C/50/D/488/1992-, el Comité de Derechos Humanos, órgano colegiado de supervisión del Pacto Internacional de Derechos Civiles y Políticos, mantenía un claro criterio: para ser considerada como víctima, la persona demandante debía estar personalmente afectada por la acción u omisión del Estado parte. Sin embargo, a partir del mencionado supuesto de hecho esta línea jurisprudencial ha mutado en cierta medida. Así, Nicholas Toonen, activista por la promoción de los derechos de los ciudadanos homosexuales en Tasmania, afirmó ser víctima de violaciones por parte del Estado Australiano de diversos preceptos del 
legislación de los Estados partes ${ }^{32}$. En otras palabras, quedan fuera del Protocolo las comunicaciones colectivas, es decir, la posibilidad de que el Comité reciba y examine comunicaciones provenientes de instituciones nacionales de Derechos Humanos o de organizaciones no gubernamentales -tanto nacionales como internacionales ${ }^{33}$ - que denuncien violaciones recurrentes de los derechos que asistan a un grupo de presuntas víctimas en el que no todas pueden ser debidamente identificadas ${ }^{34}$.

Finalmente, por lo que a las medidas de protección se refiere, el Comité -mientras el procedimiento siga abierto-, puede solicitar a los Estados parte que adopten todas las medidas de protección necesarias para garantizar que las personas sujetas a su jurisdicción no sean objeto de ninguna vulneración de sus derechos humanos, maltrato o intimidación como consecuencia de haberse comunicado o cooperado con dicho organismo internacional -artículo $4.1 \mathrm{del}$ Protocolo y 4 del Reglamento de aplicación ${ }^{35}$. Estas medidas de protección no

Pacto Internacional de Derechos Civiles y Políticos (artículos 2, 17 y 26). Esta vulneración era producto de dos disposiciones del Código Penal de Tasmania que consideraban delitos diversas formas de contacto sexual entre hombres. El Comité de Derechos Humanos al examinar la admisibilidad de la comunicación, con respecto a la cuestión de si el autor podía ser considerado víctima en el sentido del artículo 1 del Protocolo facultativo, observó que las disposiciones impugnadas por el autor no habían sido aplicadas por las autoridades judiciales de Tasmania desde hacía varios años. No obstante, consideró que el autor había hecho esfuerzos razonables por demostrar que la amenaza de aplicación y los efectos generalizados del mantenimiento de esas disposiciones sobre las prácticas administrativas y la opinión pública le habían afectado y continuaban afectándole personalmente. Por consiguiente, el Comité concluyó que el autor podía ser considerado como víctima y que sus denuncias eran admisibles ratio temporis. Un resumen de esta evolución la encontramos detallada en ZaYAS (2009), pp. 46-47.

32 El Comité de los Derechos del Niño, instituciones nacionales de derechos humanos, ONG(s) y el Unicef, se mostraron favorables a la inclusión de un procedimiento de comunicaciones colectivas en el Protocolo facultativo, pues estimaron que colmaba una laguna de los mecanismos de protección, en especial con los niños y niñas que pertenecen a grupos vulnerables, como los internados en instituciones, los que son víctimas de la prostitución, o los sometidos a prácticas tradicionales. Incluso, se barajó la posibilidad de admitirlas a través de una cláusula opting o contracting in. A pesar de ello, no lograron su cometido. AsAMBLEA GENERAL DE LAS NACIONES UnidAs (2010a), párrafos 13-15.

33 Ravetllat (2018), pp. 1-6; Ravetllat (2017a), pp. 255-306; y Ravetllat (2017b), pp. 5-7.

34 En cambio, esta posibilidad sí se admite tanto en la Carta Africana sobre Derechos y el Bienestar del Niño de 1990, como en el Protocolo adicional de la Carta Social Europea de 1995. En este sentido, BeKKER (2013), pp. 1-29 y BELORGEY (2011), pp. 787-806.

35 Estos preceptos son copia cuasi literal del artículo 11 del Protocolo facultativo de la Convención sobre la eliminación de todas las formas de discriminación contra la Mujer, de 6 de octubre de 1999, y del artículo 13 del Protocolo facultativo del Pacto Internacional de Derechos Económicos, Sociales y Culturales, de 10 de diciembre de 2008. 
deben confundirse con las medidas provisionales -o cautelares-, pues su propósito no es el de prevenir daños irreparables que afecten al objeto de la comunicación misma, sino proteger a personas que puedan sufrir represalias o consecuencias adversas en relación con los hechos denunciados en la comunicación, o por su cooperación con el Comité en el esclarecimiento de los hechos investigados ${ }^{36}$.

\subsection{Medidas provisionales}

A tenor de lo preceptuado en el artículo 6 del Protocolo facultativo -y desarrollado en el artículo 7 del Reglamento de aplicación-, el Comité, tras recibir una comunicación y antes de pronunciarse sobre el fondo del asunto, puede, en cualquier momento, dirigirse al Estado parte interesado, para que este estudie con urgencia, la viabilidad de adoptar las medidas provisionales necesarias en circunstancias excepcionales, para evitar posibles daños irreparables a la víctima o víctimas de la presunta vulneración ${ }^{37}$.

Diversas delegaciones, así como expertos independientes -incluidos los miembros del Comité de los Derechos del Niño-y representantes de diversas ONGs, mostraron su oposición a incluir en los mentados preceptos la expresión "en circunstancias excepcionales" por considerarla excesivamente restrictiva, además de entender que la propia noción de "daño irreparable" ya refleja suficientemente el carácter excepcional de este tipo de medidas.

La no adopción por el Estado parte de medidas cautelares después de recibir una solicitud del Comité, es considerada por este como un incumplimiento de las obligaciones asumidas por el mismo bajo la Convención sobre los Derechos

\footnotetext{
36 Durante los debates de elaboración del Protocolo facultativo se opinó que estas medidas debían aplicarse no solo a los niños o niñas presuntamente víctimas, sino también a los niños o niñas implicados de alguna forma en un procedimiento de comunicación, los miembros de la familia, así como los representantes que presentan una comunicación al Comité, incluidas las organizaciones. AsAMBLEA GENERAL DE LAS NACIONES UNIDAS (2011a), párrafo 31.

37 En el caso I.A.M. c. Dinamarca, de 25 de enero de 2018 -comunicación No 3/2016, CRC/ C/77/D/3/2016-, el Grupo de Trabajo sobre las comunicaciones actuando en nombre del Comité, pidió al Estado parte -en este caso Dinamarca- que se abstuviera de devolver a la autora y a su hija a su país de origen (Somalia) mientras su caso estuviera siendo examinado por el Comité. En virtud de ello, Dinamarca suspendió la ejecución de la orden de expulsión contra la autora y su hija. Algo similar acaeció en el caso Z.Y. y J.Y. c. Dinamarca, de 31 de mayo de 2018 -comunicación No 7/2016, CRC/C/78/D/7/2016-. En esta ocasión, el Grupo de Trabajo sobre las comunicaciones solicitó al Estado parte -nuevamente Dinamarcaque no expulsará de su territorio a los autores y a su hijo a Afganistán mientras su caso estuviera siendo conocido por el Comité. El Estado suspendió la ejecución de la orden de expulsión.
} 
del Niño. Además, atendiendo a los hechos específicos denunciados, la decisión de adoptar medidas cautelares puede ser provisional. Ante tal tesitura, el Estado es informado de que la adopción de tales medidas puede ser revisada a la luz de la información que él mismo vaya suministrando al efecto.

Finalmente, y con independencia de si la solicitud para la adopción de medidas cautelares tiene el carácter o no de provisional, el Estado puede, en cualquier etapa del procedimiento, instar al Comité para que levante dicha solicitud. La información proporcionada por el Estado para justificar tal petición debe ser precisa y enfocarse, preferiblemente, en temas vinculados con la admisibilidad y no tanto con el fondo del asunto ${ }^{38}$. Una vez efectuado este requerimiento, el mismo es transmitido al autor de la comunicación, por un plazo breve, para darle la posibilidad de formular los comentarios que estime oportunos. Recibidas estas observaciones, o si el autor no las formula dentro del plazo establecido, el relator especial o grupo de trabajo adoptan una decisión al respecto con base en la información contenida hasta ese momento en el expediente.

\subsection{Requisitos de admisibilidad de las comunicaciones individuales}

Los requisitos de admisibilidad son los enumerados en el artículo 7 del Protocolo facultativo que, si bien lleva por rúbrica "admisibilidad", en realidad lista las causales que deben llevar al Comité de los Derechos del Niño a declarar inadmisible una comunicación. En otras palabras, del precepto extraemos, a sensu contrario, los requisitos formales que debe reunir toda comunicación para que sea aceptada por el órgano ginebrino. Analicemos pues cuáles son estos elementos.

\subsubsection{No ser anónimas y presentarse por escrito}

En primer lugar, es necesario que la comunicación no sea anónima y que se presente por escrito ${ }^{39}$. En este sentido, en el formulario deben precisarse con

38 BeCO (2013), p. 374.

39 Originariamente, junto a la exigencia de que la comunicación fuera por escrito, se preveía que ello era sin perjuicio de que el Comité de los Derechos del Niño pudiera admitir evidencias no escritas en apoyo de las alegaciones contenidas en las comunicaciones. Esta última mención fue eliminada del redactado final del Protocolo facultativo -artículo 7.b)-, a pesar de existir un aparente consenso al respecto. Sin ir más lejos, el Protocolo facultativo de la Convención sobre derechos de las personas con discapacidad no contiene esta exigencia (adaptando, de este modo, el procedimiento de comunicaciones a la posibilidad 
claridad: nombre completo de la persona, nacionalidad y fecha de nacimiento, así como un domicilio a efectos de correspondencia en el Comité. Además, para el caso de que la comunicación se presente en nombre de otra persona o un grupo de ellas -tal y como autoriza el artículo 5.1 del Protocolo y $13.2 \mathrm{del}$ Reglamento de aplicación- deberán también indicarse -como no podría ser de otra forma- los datos personales del o los representados. Para este último caso, hay que adjuntar al formulario la autorización expresa del poderdante, a menos que el autor pueda justificar el actuar en su nombre sin tal consentimiento, siempre que ello obedezca, por supuesto, al interés superior del niño o grupo de niñas o niños presuntamente víctimas de vulneraciones ${ }^{40}$.

De acuerdo con la práctica del Comité, es relevante destacar la importancia de tomar en consideración si la persona que presenta la comunicación es menor o mayor de edad. Para el primero de los casos, es decir, si el sujeto no ha alcanzado aún la mayoridad, el escrito que contiene la queja debe ser inmediatamente reenviado por el Secretario General -Unidad de solicitudes- al grupo de trabajo encargado de entender de esa comunicación. Ello, incluso si prima facie pareciera que dicha petición es fundadamente inadmisible. Asimismo, la Unidad de solicitudes debe acusar recibo de la comunicación empleando un lenguaje amigable, con la mayor celeridad posible y siempre dentro de las dos semanas siguientes a la fecha de su recepción. Para el segundo de los supuestos, en cambio, cuando la comunicación es presentada por un adulto -en representación de un niño, niña o adolescente-, la petición debe ser examinada y validada por la Unidad de solicitudes, que podría llegar a rechazarla si la considera claramente infundada.

\footnotetext{
real de que personas en situación de discapacidad, incluida la discapacidad intelectual, puedan tener acceso al Comité de los Derechos de las Personas con Discapacidad). Precisamente por ello, el artículo 16.3, apartado f) del Reglamento de aplicación admite la posibilidad de que junto con la comunicación presentada por escrito se "proporcione material no escrito" a fin de complementarla. La exclusión de esta mención del redactado del Protocolo facultativo provocó las quejas de los representantes de las ONGs, más partidarios de incluir tal previsión en el texto del Protocolo y no en sus reglas de procedimiento. En este sentido, Erdem Türkelli, Vandenhole y Vandenbogaerde (2013), p. 39. También en esta misma línea se ha pronunciado reiteradamente el propio Comité DE los Derechos del Niño (2009), párr. 21, al apuntar que "la plena aplicación del artículo $12 \mathrm{CDN}$ exige el reconocimiento y respeto de las formas no verbales de comunicación, como el juego, la expresión corporal y facial y el dibujo y la pintura". Así como en su posterior Comité de los DeReChos del NiÑo (2016), párr. 23, que estipula que "es necesario introducir mecanismos de denuncia y reparación seguros y accesibles con competencias para examinar las denuncias formuladas por los adolescentes".

40 BECO (2013), p. 375.
} 
Finalmente, apuntar que la identidad de toda persona o grupo de personas involucradas en las diligencias emprendidas en virtud del Protocolo no será revelada públicamente sin su consentimiento expreso. Además, todas las fases del procedimiento se desarrollan bajo una estricta confidencialidad. Solo se hace público un resumen del procedimiento y del dictamen en los informes periódicos del Comité de los Derechos del Niño a la Asamblea General de las Naciones Unidas. En este punto, no deben confundirse las nociones de anonimato y confidencialidad. Así, la transmisión de la comunicación del Comité de los Derechos del Niño al Estado parte demandado debe ser confidencial, es decir, no pública, lo que no significa anónima, pues si así fuera, esta circunstancia iría en detrimento de las facultades del Estado de examinar la situación y de ofrecer una reparación adecuada. Dicho de otra forma, el Estado no sabría en beneficio de quién deben ir las acciones de reparación.

\subsubsection{No constituir un abuso del derecho o ser incompatible con las disposiciones de la Convención y/o sus Protocolos facultativos}

La primera de las causales contenida en el artículo 7 punto c) del Protocolo facultativo, al hacer mención como motivo de inadmisibilidad a que la comunicación "no constituya un abuso del derecho a presentar tales comunicaciones", entendemos que, en realidad, trata de evitar la tentación de contemplar al Comité de los Derechos del Niño como un órgano de apelación ante una decisión doméstica que no satisfaga las pretensiones del denunciante. Sin embargo, no es tarea del Comité ginebrino revaluar los hechos que motivaron la demanda en el orden interno, ni reinterpretar el Derecho nacional del Estado denunciado. Este mecanismo cuasi jurisdiccional no se erige en una última instancia, sino que, por el contrario, debe limitarse a analizar la adecuación del comportamiento estatal a las obligaciones asumidas conforme a la Convención y los Protocolos facultativos del año 2000, todo ello a partir de los hechos que han sido establecidos previamente por los tribunales nacionales.

Asimismo, el inciso segundo de esta causal de inadmisibilidad, al aludir a la "incompatibilidad de la comunicación con las disposiciones de la Convención y/o de sus Protocolos facultativos", ha sido utilizada por el Comité para dejar fuera de su conocimiento aquellos supuestos de hecho en que la presunta víc- 
tima no acredita ser menor de edad ${ }^{41}$, o cuando la posible vulneración de los preceptos contenidos en la Convención afecta a una persona adulta y no a un sujeto que no haya alcanzado todavía los dieciocho años de edad ${ }^{42}$.

\subsubsection{No haya sido examinada por el Comité o esté siendo o haya sido sometida a otro procedimiento de investigación o solución internacional}

\section{El Comité de los Derechos del Niño tampoco admitirá aquellas comuni-} caciones sobre un asunto respecto al cual ya se haya pronunciado o que esté siendo o haya sido examinado a través de otro procedimiento de investigación o solución internacional de naturaleza equivalente. Se trata de la consagración convencional del principio non bis in idem, que, en esta materia, busca evitar que la supuesta violación que se denuncia mediante la comunicación sea objeto de dos pronunciamientos, provengan del mismo o de diferentes órganos. Este requisito supone que las presuntas víctimas de una o más violaciones a

41 Esto sucede en el caso Y.M. c. España, de 31 de mayo de 2018 -comunicación No 8/2017, CRC/ C/78/D/8/2016-. En este supuesto, la Policía Nacional española interceptó una patera en la que viajaba el autor de la comunicación, de nacionalidad argelina, cuando pretendía acceder de forma irregular a territorio español. En el momento de su detención, se encontraba indocumentad y manifestó ser menor de edad. No obstante, tras practicársele pruebas médicas óseas para comprobar tal afirmación, se consideró por parte de las autoridades españolas que la persona era de dieciocho años. Frente a la queja individual presentada ante el Comité de los Derechos del Niño, este considera, sin pronunciarse sobre la cuestión de fondo, que existe un documento oficial expedido por el Consulado de Argelia en Barcelona -lugar dónde había sido trasladado el autor- en que se constata que el mismo era mayor de edad. Y con base en tal evidencia declara inadmisible la comunicación por ser "incompatible con las disposiciones de la Convención". Para un análisis actualizado de la situación que viven en España las personas menores de edad inmigrantes no acompañadas, GARCía (2016), pp. 1-27.

42 Tal afirmación la extraemos del caso A.A.A. c. España, de 30 de septiembre de 2016 - comunicación No 2/2015, CRC/C/73/D/2/2015-. La autora es tía paterna de una niña de 3 años de edad y mantiene un notorio enfrentamiento con su hermano, padre de la niña, y con la esposa de este. Ello, junto a unos supuestos problemas familiares de herencia, propiciaron que el matrimonio perdiera todo contacto con la familia paterna, incluida la autora, y que impidiera todo contacto de sus miembros con la pequeña. Pues bien, A.A.A., mayor de edad, tras agotar todos los recursos internos disponibles solicitando un régimen de visitas entre ella y su sobrina, presenta una comunicación ante el Comité de los Derechos del Niño, en nombre propio y en el de su sobrina, alegando la vulneración de diversos preceptos de la Convención sobre los Derechos del Niño. Ante ello, el órgano ginebrino, y en lo que ahora nos compete, considera que sostener, como lo había hecho la autora, una posible vulneración de sus derechos, como adulta, contenidos en la Convención, se torna como "incompatible con las disposiciones del mentado tratado internacional", pues este protege los derechos de los niños, niñas y adolescentes, y no así los derechos de los adultos. Y precisamente esta argumentación es una de las causas que llevan al Comité a declarar que la queja es inadmisible. 
los Derechos Humanos consagrados en instrumentos internacionales, y que se encuentren bajo la jurisdicción de un Estado que ha aceptado someterse a varios procedimientos de comunicaciones y que reconoce competencias a instancias jurisdiccionales supranacionales -como podrían ser el Tribunal Europeo de Derechos Humanos o la Corte Interamericana de Derechos Humanos-, deberán decantarse por una de esas hipotéticas vías. Dicho de otra forma, la violación de derechos solo podrá ser denunciada a través de uno de los procedimientos establecidos, quedando en manos del denunciante la elección de uno de ellos, pero teniendo claro que al optar por uno se excluye a los demás.

Cada una de esas posibles alternativas presenta sus ventajas e inconvenientes, por lo que resulta imprescindible analizar con la debida cautela los pros y contras que ofrecen cada una de ellas. Por ejemplo, deben tomarse en consideración, entre otros, los siguientes factores: posibilidad de actuar a partir de denuncias individuales; coste económico aparejado -algunos procedimientos requieren de la intervención de un abogado y otros, como la comunicación ante el Comité de los Derechos del Niño, no-; posibilidad de obtener una reparación a través del mecanismo utilizado; fuerza vinculante para el Estado de la resolución o decisión adoptada; y, plazos de presentación (que en el caso del Comité de los Derechos del Niño se limita a un año contado desde el agotamiento de los recursos internos).

\subsubsection{Agotar todos los recursos internos disponibles}

Previo a presentar una comunicación ante el Comité de los Derechos del Niño reportando una supuesta vulneración de los principios o derechos dimanantes de la Convención o sus Protocolos facultativos, se exige, como regla general, que el solicitante -cualquiera sea su edad, actúe o no a través de un representante ${ }^{43}$ - haya agotado todos los recursos internos que se encuentren disponibles. Este requisito para la admisibilidad de la comunicación es de general aplicación en el sistema internacional de protección de los Derechos Huma-

\footnotetext{
43 Con esto se quiere destacar que la condición de niña, niño o adolescente no es suficiente per se para eximir a estas personas del agotamiento de los recursos internos. Sin embargo, si su condición etaria le genera algún tipo de discriminación o le impide su acceso a defensa letrada, la conclusión será inversa. En este sentido, puede verse el razonamiento de la CIDH en la Opinión Consultiva OC-11/90, de 10 de agosto de 1990, párrafos 20 a 31.
} 
nos $^{44}$, pues se entiende que la intervención de los órganos internacionales tiene un carácter subsidiario, coadyuvante y complementario al sistema nacional ${ }^{45}$. De esta forma, en la especie, el Estado tiene la preferencia para hacerse cargo y resolver mediante sus propios órganos de administración de justicia, las denuncias por violaciones a derechos consagrados en la Convención o en alguno de sus Protocolos, pudiendo recurrirse al sistema internacional solo cuando se hayan empleado todas las herramientas procesales previstas y no se consiga una solución satisfactoria del caso ${ }^{46}$.

En esta perspectiva, se debe tener presente que los recursos a los que se hace referencia en la norma son aquellos de carácter jurisdiccional, excluyéndose cualquier tramitación o procedimiento de otra naturaleza -principalmente, administrativo- que se haya llevado a cabo ${ }^{47}$. Se trata, por tanto, de recursos -ordinarios o extraordinarios ${ }^{48}$-, que deben ser conocidos y resueltos por un

44 En efecto, esta exigencia ha sido prevista por una serie de instrumentos internacionales, entre ellos: art. 46 de la Convención Americana de Derechos Humanos; art. 35.1 del Convenio Europeo de Derechos Humanos; art. 56 de la Carta Africana sobre los Derechos Humanos y de los pueblos; y art. 5.2 del Protocolo Facultativo del Pacto Internacional de Derechos Civiles y Políticos

45 Faúndez (2007), p. 46. En el mismo sentido: GonzÁlez (2010), p. 246; GonZÁlez (2009), p. 47; Paúl (2014), pp. 626 y ss. De esta forma, el Preámbulo de la CADH establece: "Reconociendo que los derechos esenciales del hombre no nacen del hecho de ser nacional de determinado Estado, sino que tienen como fundamento los atributos de la persona humana, razón por la cual justifican una protección internacional, de naturaleza convencional coadyuvante o complementaria de la que ofrece el derecho interno de los Estados americanos".

46 Sobre este punto, el Tribunal Europeo de Derechos Humanos ha señalado que él solo desempeña un rol subsidiario a los sistemas nacionales de protección de derechos fundamentales, de modo que son los órganos nacionales los que deben tener la primera opción de resolver los asuntos. European CourT OF Human Rights (2019), p. 21.

47 Faúndez (2007), p. 50.

48 Se ha argumentado que la CIDH ha sostenido, en principio, que el agotamiento solo debe referirse a los recursos ordinarios. Para ello se ha tenido a la vista la sentencia dictada en el caso Herrera Ulloa vs. Costa Rica, de 2 de julio de 2004, párrafo 85: "La Corte considera pertinente señalar que "la acción de inconstitucionalidad" es de carácter extraordinario, y tiene por objeto el cuestionamiento de una norma y no la revisión de un fallo. De esta manera, dicha acción no puede ser considerada como un recurso interno que deba necesariamente ser siempre agotada por el peticionario". De la misma forma, la Comisión Interamericana de Derechos Humanos ha sostenido: "La jurisprudencia del sistema ha establecido que si bien en algunos casos los recursos extraordinarios pueden ser adecuados para enfrentar violaciones de derechos humanos, como norma general, los únicos recursos que es necesario agotar son aquellos cuyas funciones, dentro del sistema jurídico, son apropiadas para brindar protección tendiente a remediar una infracción de determinado derecho legal, por lo que en principio, se trata de recursos ordinarios, y no extraordinarios" (Informe No 59/16, petición 89-07, párrafo 5). Empero, Faúndez afirma que para determinar el cumplimiento de esta exigencia no es oportuno ni necesario atender a la naturaleza ordinaria o extraordinaria del recurso, sino más bien a si ellos resultan o no idóneos para reparar la situación jurídica infringida. FAúndez (2007), p. 53. 
órgano judicial nacional, de acuerdo con un procedimiento establecido previamente por la ley y que permiten obtener una resolución que se caracteriza por tener fuerza ejecutoria ${ }^{49}$. De esta manera, estos recursos son aquellos que procedan específicamente en el proceso judicial que se haya incoado a partir de la vulneración de derechos denunciada, por tanto, la parte que se vea agraviada por la o las resoluciones judiciales debe haber interpuesto -en tiempo y formalos medios de impugnación que hayan sido establecidos por el legislador. Así, será el propio Estado, quien al configurar los distintos procedimientos judiciales, determinará, en principio, cuáles son aquellos recursos que deben ser agotados por las partes para estar en condiciones de presentar una comunicación al Comité, cuestión que, en suma, dependerá de la vía procesal que se haya elegido para alegar la conculcación de derechos. En todo caso, el interesado debe poner mucha atención en la elección del procedimiento que seguirá para tramitar su alegación, toda vez que si yerra en este aspecto no será posible considerar que ha agotado todos los recursos internos ${ }^{50}$. Sea como fuere, en el caso chileno lo normal será que -ante el inicio de un procedimiento por violación de alguno de los derechos contenidos en la Convención o en sus Protocolos facultativosel agotamiento de los recursos se producirá cuando se ocurra ante la Corte Suprema, vía recurso de apelación, casación, nulidad o revisión, dependiendo del procedimiento particular.

Usualmente el agotamiento de recursos internos deberá entenderse cumplido cuando se obtenga la respuesta del aparato jurisdiccional frente al último mecanismo de impugnación que se haya hecho valer, pues es perfectamente posible que en esta última resolución se obtenga la solución o reparación que se había solicitado al aparato de administración de justicia. Empero, lo expresado no puede entenderse como una regla absoluta, pues puede configurarse un escenario de denegación de justicia, en el que las autoridades retarden injustificadamente su pronunciamiento o, lisa y llanamente, no emitan ninguna decisión ante el recurso interpuesto, circunstancia en que la Comisión Interamericana de De-

49 Sobre este punto puede verse la sentencia dictada por la CIDH en el caso Loayza Tamayo vs. Perú, de 31 de enero de 1996, párrafo 38, letra d).

50 Comisión Interamericana de Derechos Humanos, Informe No 27/93, Caso No 11.092, Canadá, de 6 de octubre de 1993, párrafo 15. 
rechos Humanos ha entendido que se deben tener por agotados los recursos que estaban a disposición de la víctima ${ }^{51}$.

En esa perspectiva, el tercer Protocolo facultativo ha previsto expresamente algunos supuestos en los que no se exige el agotamiento de los recursos internos para declarar la admisibilidad de la comunicación. De esta forma, este requisito no será aplicable cuando los recursos se hayan prolongado injustificadamente o sea improbable que con ellos se logre una reparación efectiva de la persona o grupo de personas víctimas de la vulneración ${ }^{52}$.

Dicho de otra forma, los recursos que deben ser agotados son aquellos adecuados, idóneos y efectivos para hacer frente a la violación de derechos fundamentales que se ha denunciado ${ }^{53}$. Por tanto, para tener certeza en un caso específico respecto a qué recursos hay que agotar no basta solo con analizar el texto legal que regula la tramitación de un procedimiento judicial concreto. No se trata únicamente de un ejercicio abstracto o teórico de análisis de la regulación legal, sino de determinar tanto si las condiciones de funcionamiento del sistema jurídico nacional -en general-, como del órgano judicial llamado a pronunciarse sobre el caso -en particular-, permiten remediar la situación denunciada ${ }^{54}$, considerando si los recursos previstos por el legislador pueden

51 Comisión Interamericana de Derechos Humanos, Resolución № 18/87, Caso No 9.426, Perú, de 30 de junio de 1987, párrafo 7.

52 En este sentido, la Corte Interamericana de Derecho Humanos, en la sentencia del caso Velásquez Rodríguez vs. Honduras, de 26 de junio de 1987, párrafo 64, sostuvo: "Que sean adecuados significa que la función de esos recursos, dentro del sistema del derecho interno, sea idónea para proteger la situación jurídica infringida. En todos los ordenamientos internos existen múltiples recursos, pero no todos son aplicables en todas las circunstancias. Si, en un caso específico, el recurso no es adecuado, es obvio que no hay que agotarlo. Asi lo indica el principio de que la norma está encaminada a producir un efecto y no puede interpretarse en el sentido de que no produzca ninguno o su resultado sea manifiestamente absurdo o irrazonable".

53 Gómez y Montesinos (2013), p. 226. En el mismo sentido, el Comité de Derechos Humanos -órgano colegiado de supervisión del PIDCP- ha precisado que el requisito del agotamiento de los recursos internos abarca solamente los recursos efectivos y disponibles, en una interpretación que parece haberse hecho extensiva al resto de los Comités. Sobre el particular se pronuncia el caso William Torres Ramírez c. Uruguay -Comunicación No 4/1977, de 26 de enero de 1978, CCPR/C/10/D/4/1977- en que indicó que el Estado debía probar "que existían posibilidades razonables de que tales recursos fueran efectivos".

54 La CIDH sostuvo en el caso Ivcher Bronstein vs. Perú, sentencia de 6 de febrero de 2001, párrafo 136: “... no basta con que esté previsto por la Constitución o la ley o con que sea formalmente admisible, sino que se requiere que sea realmente idóneo para establecer si se ha incurrido en una violación a los derechos humanos y proveer lo necesario para remediarla. No pueden considerarse efectivos aquellos recursos que, por las condiciones generales del país o incluso por las circunstancias particulares de un caso dado, resulten ilusorios". 
resolverse sin retardo injustificado ${ }^{55}$ y sirven para cumplir su finalidad, esto es, reparar efectivamente a las víctimas ${ }^{56}$. Si la respuesta a cualquiera de estos puntos es negativa, no es procedente la exigencia de agotar esos recursos, debiendo admitirse a trámite la comunicación sin ello. De lo contrario, este requisito se cumpliría a través de una pantomima, un simulacro de recurso, que solo provocaría la prolongación inútil del procedimiento interno y un retraso injustificado en el acceso a la sede internacional, lo que podría generar perjuicios irreparables para las víctimas y tornar completamente estéril la intervención del Comité57.

Tal como lo ha expresado el Tribunal Europeo de Derechos Humanos ${ }^{58}$, pensamos que el agotamiento de los recursos internos debe ser interpretado con cierta flexibilidad y sin un excesivo formalismo, cuestión que también debe alcanzar a sus excepciones. De esta manera, el Comité debe propender a dar curso a la sustanciación del procedimiento, interpretando este requisito de acuerdo con el principio pro homine 59 , de modo de propender a una mayor protección a la persona o grupo de personas que denuncian una violación de derechos, permitiendo su acceso al sistema internacional establecido para estos efectos.

Ahora bien, la mera existencia de un fallo anterior en sentido negativo, aun cuando sea sobre cuestiones similares a las del caso de autos, no exime al peti-

55 La jurisprudencia de la CIDH también ha servido para establecer algunos elementos a tener en cuenta para calificar la existencia de un retardo injustificado en la tramitación de los asuntos judiciales: "La Corte ha establecido que es preciso tomar en cuenta tres elementos para determinar la razonabilidad del plazo: a) la complejidad del asunto, b) la actividad procesal del interesado, y c) la conducta de las autoridades judiciales. El Tribunal considera pertinente precisar, además, que en dicho análisis de razonabilidad se debe tomar en cuenta la afectación generada por la duración del procedimiento en la situación jurídica de la persona involucrada en el mismo, considerando, entre otros elementos, la materia objeto de controversia. Si el paso del tiempo incide de manera relevante en la situación jurídica del individuo, resultará necesario que el procedimiento corra con más diligencia a fin de que el caso se resuelva en un tiempo breve". Caso Valle Jaramillo y otros vs. Colombia, sentencia de 27 de noviembre de 2008, párrafo 155. Sobre el particular, la CIDH también ha señalado que los recursos que deben agotarse son aquellos que pueden calificarse de rápidos y eficaces, de modo que su ejercicio no se transforme en una dilación del procedimiento. Ver, caso Myrna Mack Chang vs. Guatemala, sentencia de 25 de noviembre de 2005, párrafo 204.

56 Sobre la efectividad de los recursos, ver la sentencia de la CIDH, caso Godinez Cruz vs. Honduras, de 20 de enero de 1989, párrafo 69.

57 Sobre este aspecto se ha pronunciado la CIDH: Caso Velásquez Rodríguez, sentencia de 26 de junio de 1987, párrafo 93; Caso Fairén Garbi y Solís Corrales, sentencia de 26 de junio de 1987, párrafo 92; y Caso Godínez Cruz, sentencia de 26 de junio de 1987, párrafo 95. Sobre el particular, FAúndez (2007), p. 119.

58 European Court of Human Rights (2019), p. 22.

59 Sobre el principio pro homine: Aguilar y Nogueira (2016), p. 17; Pinto (1997), p. 163; Sagüés (1998), p. 6. 
cionario de intentar valerse del recurso interno previsto, ni tampoco las meras dudas acerca de la eficacia de esos recursos o la convicción de que valerse de ellos podría hacerle incurrir en gastos. Asimismo, son inadmisibles las comunicaciones en las que el no agotamiento de los recursos internos se ha debido al vencimiento de los plazos para recurrir por inacción o negligencia imputable única y exclusivamente al actor, y no al Estado parte ${ }^{60}$. Este último aspecto puede resultar muy complicado de analizar para el Comité, especialmente en casos en que la actuación del representante o mandatario judicial del niño, niña o adolescente no se haya ajustado a la voluntad de este. Dicho de otra forma, el no ejercicio de todos los recursos disponibles será una decisión que en definitiva siempre estará en manos de los representantes adultos con que el menor cuente en el procedimiento judicial, quienes podrían desoír los deseos de este, aceptar la decisión jurisdiccional desfavorable y poner fin al juicio. Con ello, no solo subsistirá la violación de derechos denunciada a través de la vía interna, sino que se privará a la víctima de formular una comunicación ante el Comité. De ahí que este órgano debe ser muy cuidadoso al momento de rechazar la comunicación debido a la negligencia o inacción del actor en el ejercicio de los recursos internos.

\subsubsection{Ser manifiestamente infundada o no estar suficientemente fundamentada}

La comunicación debe contener unos mínimos visos de razonabilidad para que prosiga su tramitación, en caso contrario, el Comité la declarará inadmisible a tenor de lo previsto en el artículo 7 apartado f) del Protocolo facultativo. Esto es precisamente lo que acaeció en el caso A.A.A. c. España, de 30 de septiembre de 2016, en que el Comité de los Derechos del Niño consideró que la autora de la queja, que reclamaba el derecho a relacionarse con su sobrina de tres años, no acreditó suficientemente que las autoridades judiciales españolas al ponderar el interés superior de la niña, habían vulnerado el artículo 3 de la Convención sobre los Derechos del Niño ${ }^{61}$. Lo mismo ocurrió en el caso Z.Y. y J.Y. c. Dinamarca,

60 OchoA Ruiz (2004), pp. 309-310.

61 Comunicación № 2/2015 -CRC/C/73/D/2/2015-. El Comité entiende que "como regla general, es competencia de los órganos jurisdiccionales nacionales examinar los hechos y las pruebas, salvo que dicho examen sea claramente arbitrario o equivalga a una denegación de justicia. El Comité observa que las sentencias de primera instancia, apelación y casación se basaron en el interés superior de la niña para desestimar la demanda 
de 31 de mayo de 2018, al entender el Comité de los Derechos del Niño que los autores -padres de un niño afgano contra los que pesaba una orden de expulsión del territorio danés- no demostraron que existiera un riesgo personal de que se produjera una violación grave de los derechos del pequeño tras su regreso a Afganistán ${ }^{62}$. Por último, hacer referencia al caso J.A.B.S. c. Costa Rica, de 17 de enero de 2017, donde el Comité determinó que la queja era infundada por no quedar debidamente constatada la presunta vulneración del artículo 7 de la Convención -derecho a la identidad-, al no lograr el autor inscribir a sus hijos mellizos -nacidos en California vía fertilización in vitro con un óvulo de una donante y semen propio- en el Registro civil costarricense con dos apellidos: el primero del autor y el segundo de la donante de óvulo. Por el contrario, las autoridades registrales, amparándose en la legislación nacional, los inscribió con los dos apellidos paternos ${ }^{63}$.

\subsubsection{Competencia ratione temporis}

Conforme a este requisito de admisibilidad, los hechos denunciados deben haber ocurrido con posterioridad a la entrada en vigor del Protocolo facultativo para el Estado acusado, o que, habiendo comenzado antes, continúen o sus efectos se prolonguen tras dicho momento temporal. El Protocolo facultativo exige, además, que la comunicación se presente dentro de un año desde el agotamiento de los recursos internos del presunto Estado infractor, excepto si se dan circunstancias excepcionales debidamente acreditadas ${ }^{64}$. Este sería el caso,

de la autora, interés debidamente justificado en el potencial efecto perjudicial que podría suponer para la niña iniciar una relación con una pariente desconocida que mantenía un alto nivel de conflictividad con sus padres. En ausencia de información adicional que permita justificar en qué medida se habria lesionado el principio del interés superior de la niña al desestimar la demanda de la autora, el Comité considera que esta queja no ha sido suficientemente fundamentada y la declara inadmisible".

62 Los autores de esta Comunicación No 7/2016 -CRC/C/78/D/7/2016- alegaron que si su hijo entraba en territorio afgano corría el riesgo de ser asesinado, al ser considerado un hijo ilegítimo nacido fuera del matrimonio -aunque sus padres sí estaban casados, dicho enlace se celebró sin el consentimiento de la familia de la madre- y, además, de confesión cristiana y no haber sido circuncidado.

63 Comunicación No 5/2016 -CRC/C/74/D/5/2016-.

64 ONG(s), instituciones nacionales de derechos humanos, así como los miembros del Comité de los Derechos del Niño, no consideraron apropiado aplicar tales plazos por ser ello "contrario al deseo expresado de que el procedimiento de comunicaciones fuera adaptado a los niños y fácilmente accesible para ellos". ASAMBLEA General de las Naciones Unidas (2011a), párrafo 55. De esa misma opinión son Langford y Clark (2011), pp. 5-6. 
por ejemplo, de que pudiera acreditarse una situación personal del niño, niña o adolescente o de sus representantes legales -algún tipo de coacción, miedo fundado- que le impidieran poder cursar dicha comunicación dentro del plazo prestablecido. También entraría dentro de esta excepcionalidad una hipotética situación de conflictividad en el país de residencia de la persona menor de edad que complicara la presentación de la comunicación.

El Comité de los Derechos del Niño ya ha tenido la oportunidad de referirse a esta causa de inadmisibilidad contenida en el artículo $7 \mathrm{~g}$ ) del Protocolo en un par de ocasiones. Concretamente, en el caso S.C.S. c. Francia, de 25 de enero de $2018^{65}$ y en el caso A.H.A. c. España, de 4 de junio de $2015^{66}$. En el primero de los asuntos, una madre, de nacionalidad rumana y etnia romaní, presenta comunicación en nombre de sus dos hijos, y de su nieto, por su expulsión el 16 de abril de 2015 del campamento en que vivían en Champs-sur-Marne, Francia. Tras el análisis de admisibilidad, el órgano ginebrino opta por no pronunciarse sobre el fondo del asunto por falta de competencia ratione temporis, pues el Protocolo facultativo entró en vigor en Francia el 7 de abril de 2016. En el segundo de los supuestos, un ciudadano de Ghana alega la arbitrariedad de las autoridades españolas al serle denegada su condición como persona menor de edad e ignorarse la fecha de nacimiento que figuraba en su pasaporte, a pesar de que en ningún momento se impugnó su validez. El Comité tomando nota de la reclamación formulada por el autor y comprobando que todas las actuaciones de las autoridades españolas, tanto administrativas como judiciales, tuvieron lugar antes del 14 de abril de 2014, fecha de entrada en vigor en España del Protocolo facultativo, se inhabilita para examinar el fondo de la cuestión.

\subsubsection{Competencia ratione materiae}

La comunicación ha de referirse necesariamente a derechos y obligaciones contenidos en la Convención sobre los Derechos del Niño y/o sus Protocolos facultativos sustantivos. Lo que se traduce en que deben invocarse presuntas vulneraciones de preceptos contenidos en cualquiera de esos instrumentos internacionales, pero no en otros.

65 Comunicación No 10/2017, de 25 de enero de 2018 -CRC/C/77/D/10/2017-.

66 Comunicación No 1/2014, de 4 de junio de 2015 -CRC/C/69/D/1/2014-. 
Así, por ejemplo, en el caso A.A.A. c. España, de 30 de septiembre de 2016, la comunicación fue rechazada, entre otros motivos, por alegarse por parte de la autora supuestas violaciones del Pacto Internacional de Derechos Civiles y Políticos, que caen, en palabras del propio Comité, "fuera del ámbito del presente procedimiento de comunicaciones" 67 .

\subsection{Resultado del procedimiento de comunicaciones}

El procedimiento puede concluir bien con una decisión de no admisibilidad o bien con un dictamen sobre el fondo del asunto, en que el Comité de los Derechos del Niño indica si, sobre la base de las informaciones suministradas por las partes, considera que hubo o no vulneración de la Convención sobre los Derechos del Niño o cualquiera de sus dos Protocolos facultativos sustantivos. No se prevé posibilidad alguna de recurso u oposición a tal dictamen.

El dictamen emitido por el Comité de los Derechos del Niño ha de fundamentarse en los datos aportados por las partes en las declaraciones orales obtenidas durante el procedimiento, así como en la documentación procedente de los órganos de las Naciones Unidas o de cualquier otro organismo especializado que pueda ayudar a resolver la controversia.

En caso de constatarse la violación, el Comité nunca condena explícitamente al Estado. Por el contrario, la resolución se redacta en un tono sumamente cuidadoso y conciliador -el Comité estima, considera, recomienda-; al fin y al cabo, se trata de una simple opinión o recomendación, sin carácter vinculante para las partes, y el Estado es libre o no de cumplirla ${ }^{68}$. En otras palabras, la finalidad del dictamen no consiste en deducir la responsabilidad internacional del Estado por el incumplimiento de sus obligaciones convencionales, sino en animar al Estado a cumplir con sus compromisos internacionales. Para ello es fundamental que el Comité en el desempeño de esta tarea evite adoptar un planteamiento de confrontación, sino que, por el contrario, potencie el diálogo, la persuasión y la cooperación ${ }^{69}$.

67 Comunicación No 2/2015, de 26 de octubre de 2016 -CRC/C/73/D/2/2015-.

68 Philips (2013), p. 8.

69 Uno de los primeros casos en que el Comité de los Derechos del Niño considera que un Estado parte ha vulnerado alguno de los preceptos de la Convención es el caso I.A.M. c. Dinamarca, de 28 de enero de 2018 -Comunicación No 3/2016, CRC/C/77/D/3/2016-. En este supuesto, y ante la orden de expulsión de una madre de nacionalidad somalí - de Puntlandia para ser más exactos- junto con su hija por parte de 
En última instancia, la verdadera eficacia de estos dictámenes radica en la presión política y moral que pueda ejercerse sobre el Estado acusado, en lo que se conoce como la "movilización de la vergüenza", es decir, no se trata de una sanción jurídica, sino de tipo moral o político, por lo que el procedimiento no redunda necesariamente en una mejora de la situación del o los individuos reclamantes. Además, con el objeto de ejercer una presión adicional sobre los Estados con vistas a que cumplan con lo estipulado en los dictámenes, el artículo 11 del Protocolo y el artículo 28 de su Reglamento de aplicación, prevén un sistema de seguimiento, que solo el tiempo determinará cuál es su verdadero nivel de eficacia.

En este sentido, a la mayor brevedad posible, y siempre en un plazo máximo de seis meses, a partir de la transmisión del dictamen del Comité sobre una comunicación o de su decisión por la que se dé por concluido el examen de la misma a través de un acuerdo de solución amigable, el Estado parte presentará por escrito al Comité una respuesta en la que se incluirá información acerca de las medidas adoptadas o que se tenga previsión de adoptar a la luz del mentado dictamen o del acuerdo de solución amigable ${ }^{70}$.

Además, y con la clara intención de dar un seguimiento adecuado a las recomendaciones efectuadas por el Comité de los Derechos del Niño, las reglas de procedimiento estipulan, siguiendo el modelo iniciado ya por el Comité de Derechos Humanos, la designación de un relator o grupo de trabajo encargado de verificar las medidas adoptadas por el Estado parte ${ }^{71}$.

las autoridades danesas. Se alega por la autora que dicha expulsión significará poner en grave peligro a la niña, en especial de ser sometida a una mutilación genital femenina. Tras admitir a trámite la comunicación, por reunir todos los requisitos exigidos por el artículo 7 del Protocolo facultativo, el Comité se pronuncia sobre el fondo y considera que "el Estado parte no tuvo en cuenta el interés superior de la niña al evaluar el supuesto riesgo al que se exponía la hija de la autora de ser sometida a la mutilación genital femenina en caso de ser expulsada a Puntlandia, ni adoptó las salvaguardias debidas para garantizar el bienestar de la niña a su regreso, lo que supone una vulneración de los artículos 3 y 19 de la Convención".

70 En igual medida, los artículos 11.2 del Protocolo y 28.4 del Reglamento de desarrollo, atribuyen al Comité de los Derechos del Niño la posibilidad de "solicitar al Estado parte que incluya información sobre las medidas adoptadas en respuesta a su dictamen, sus recomendaciones o su decisión por la que se dépor concluido el examen de la comunicación a raiz de un acuerdo de solución amigable en los informes que presente ulteriormente de conformidad con el artículo 44 de la Convención sobre los Derechos del Niño, el artículo 12 del Protocolo facultativo relativo a la venta de niños, la prostitución infantil y la utilización de niños en la pornografía o el artículo 8 del Protocolo facultativo relativo a la participación de niños en los conflictos armados".

71 Por su parte Schmidt (2009), pp. 25-34, nos ofrece una lectura un tanto crítica con respecto a la labor de los relatores o grupos de trabajo encargados del seguimiento de los dictámenes adoptados por los mecanismos de supervisión de derechos humanos en el sistema de Naciones Unidas. 


\section{Comunicaciones entre Estados}

Este mecanismo de reclamación interestatal, que toma como modelo el sistema fijado en el artículo 32 de la Convención Internacional para la protección de todas las personas contra las desapariciones forzosas ${ }^{72}$, permite a los Estados partes en la Convención sobre los Derechos del Niño presentar una queja contra otro Estado parte en la misma, si consideran que este segundo Estado no está cumpliendo con las obligaciones que le impone el tratado internacional (artículo 12) ${ }^{73}$.

Efectivamente, tal y como establece la doctrina internacionalista, este mecanismo se caracteriza por estar sometido a una suerte de doble llave facultativa, en tanto recae sobre los Estados partes la carga de hacer una declaración adicional a su manifestación de voluntad reconociendo la competencia del Comité para proceder a tales efectos. Sobre la dualidad del carácter facultativo del procedimiento se establece que el órgano ginebrino "no admitirá comunicaciones que se refieran a un Estado parte que no haya hecho esa declaración", ni las "procedentes de un Estado parte que tampoco la haya efectuado" 4.

Si bien es cierto que el Protocolo facultativo del año 2011 regula esta posibilidad, no debe obviarse la infrautilización que de esta vía se ha venido realizando a lo largo del tiempo ${ }^{75}$. Ha tenido que aguardarse hasta el año 2018 para que, por vez primera en la historia, se presentaran dentro del sistema de mecanismos convencionales de protección de los Derechos Humanos de las Naciones Unidas, tres comunicaciones interestatales, concretamente frente al Comité para la Eliminación de la Discriminación Racial -a tenor de lo dispuesto

\footnotetext{
72 Según Laso (2014), p. 175, desde un punto de vista dogmático pone de relieve "la creación de una garantía colectiva en la aplicación del Tratado, a través de la cual se expresa el interés de todos los Estados en la aplicación efectiva de todas las disposiciones reconocidas en el acuerdo, reafirmando el carácter procedimental erga omnes de sus disposiciones". Por su parte ОсноА (2004), pp. 387-390, nos presenta un análisis exhaustivo de la génesis de este tipo de mecanismos de reclamaciones interestatales aplicados a tratados de protección de derechos humanos.

$73 \mathrm{Al}$ igual que sucediere en las comunicaciones individuales no se admiten quejas in abstracto, por el contrario, los Estados deben referirse a vulneraciones específicas que estén afectando a una persona o grupo de personas menores de edad.

74 Riquelme (2014), p. 33.

75 Entiende Ssenjonjo (2010), p. 83, que a pesar de que este mecanismo no sea particularmente utilizado en la práctica, su mera previsión dota a la diplomacia internacional de una herramienta muy útil.
} 
en el artículo 11 de la Convención Internacional sobre la Eliminación de todas las Formas de Discriminación Racial76-.

Las principales razones que explican el por qué este mecanismo no ha sido empleado hasta una fecha tan reciente son de diversa índole. En primer lugar, obedece a motivaciones de carácter político, como el temor a que el mecanismo pueda convertirse en arma arrojadiza en manos de los Estados. En segundo término, también existen argumentaciones de carácter más bien técnico que disuaden del empleo de este instrumento. Para empezar, en la mayoría de tratados de derechos humanos - no siendo la Convención sobre los Derechos del Niño una excepción- se configura esta posibilidad como meramente facultativa, a través de cláusulas opting o contracting in, habiendo sido en general escasamente aceptada por los Estados. Por si ello fuera poco, el mecanismo está trabado por múltiples obstáculos procesales: el principal, agotar los recursos internos del Estado presuntamente infractor antes de presentar la reclamación en el plano internacional. Por último, los resultados que se prevé que se alcancen una vez concluido el procedimiento son extremadamente débiles. De no lograrse en algún momento del procedimiento una solución amistosa entre las partes enfrentadas ${ }^{77}$, el Comité de los Derechos del Niño debe limitarse a redactar un informe en el que se contenga un resumen de los hechos acaecidos y se detallen las recomendaciones dirigidas al Estado infractor, las cuales, como su propio nombre indica, no son de obligado cumplimiento. En definitiva, existe un alto riesgo de que, una vez utilizado este instrumento, se genere o acreciente una

76 Las comunicaciones interestatales recibidas fueron las presentadas por Qatar contra el Reino de Arabia Saudita (Interstate communication ICERD-ISC-2018/1) y contra Emiratos Árabes Unidos (Interstate communication ICERD-ISC-2018/2), ambas de 8 de marzo de 2018, y por el Estado de Palestina contra Israel (Interstate communication ICERD-ISC-2018/3), el 23 de abril de 2018. Durante su 970 período de sesiones (26 de noviembre al 14 de diciembre de 2018), el Comité para la Eliminación de la Discriminación Racial decidió examinar todas las cuestiones preliminares relacionadas con las tres quejas interestatales recibidas en su $98^{\circ}$ período de sesiones (23 de abril al 10 de mayo de 2019). Finalmente, en comunicado emitido por el propio Comité de expertos el 10 de mayo de 2019, se anunció que "The Committee had examined three interstate communications submitted under article 11 of the Convention: one by Qatar against Saudi Arabia; one by Qatar against the United Arab Emirates; and another by the State of Palestine against Israel. While it had held hearings on these communications, the Committee had decided not to take any decisions, due to the legal complexity of the issues broached and a lack of resources".

77 Este desacuerdo entre dos Estados tratará de ser resuelto utilizando los buenos oficios o las facultades de conciliación del Comité de los Derechos del Niño, teniendo siempre en cuenta que la solución a la que se llegue habrá de estar basada en el respeto del principio del interés superior del niño. 
tensión entre Estados, sin que los resultados obtenidos a cambio sean tangibles en favor de los individuos.

\section{INVESTIGACIONES EN CASO DE VIOLACIONES} GRAVES O SISTEMÁTICAS

Por último, apuntar que el Protocolo facultativo de la Convención sobre los Derechos del Niño (art. 13) prevé la posibilidad de iniciar, de oficio, un procedimiento de investigación, si el Comité de los Derechos del Niño recibe información fidedigna que indique violaciones graves o sistemáticas por un Estado parte de los derechos enunciados en la Convención y/o en sus Protocolos facultativos sustantivos. Estas evidencias pueden proceder de cualquier medio debidamente contrastado: sociedad civil, instituciones nacionales o internacionales de defensa de los derechos humanos, medios de comunicación, entre otros.

El Protocolo dispone el carácter obligatorio de la investigación de no mediar una expresa declaración de exclusión (opting out), que los Estados partes podrán formular en el momento de firmar, ratificar o adherirse al instrumento internacional.

Establecida la competencia del Comité, se requiere la plena colaboración del Estado implicado. De modo que una vez que el órgano ginebrino reciba "información fidedigna que indique vulneraciones graves o sistemáticas" por parte del Estado parte, lo invitará a colaborar en su examen, así como a presentar sus propias observaciones. El Comité debe designar a uno o más de sus miembros para que elaboren con carácter urgente un informe acerca de los hechos acaecidos; e, incluso, cuando se justifique, y siempre contando con el consentimiento del Estado implicado, la investigación puede incluir una visita a su territorio.

Destacar que el Comité de los Derechos del Niño ya empleó, por vez primera, esta vía de actuación el 22 de julio de 2016, cuando recibió una documentación - informes realizados por el Instituto Nacional de Derechos Humanos, el informe Jeldres- en relación a la situación de los niños, niñas y adolescentes privados de entorno familiar que se encontraban en centros residenciales de Chile, bajo control directo o indirecto del Servicio Nacional de Menores. Los hechos descritos indicaban una posible vulneración grave y sistemática de los derechos enunciados en la Convención. Dicha información fue completada con documentos oficiales estatales, de la Cámara de Diputados y de la Fiscalía. Asimismo, se designó a dos miembros del Comité -Jorge Cardona y José Rodríguez- para que llevasen a cabo las debidas diligencias de investigación y 
realizasen una visita sobre el terreno. Finalmente, el Comité consideró que el Estado chileno vulneraba diversos preceptos de la Convención sobre los Derechos del Niño y le instó para que tomara medidas al respecto ${ }^{78}$.

\section{Conclusiones}

Cumplidos cinco años desde la entrada en vigor del Protocolo facultativo de la Convención sobre los Derechos del Niño relativo a un procedimiento de comunicaciones, este mecanismo se enfrenta a diversos desafíos, del éxito con que se resuelvan dependerá, en gran medida, su futura eficacia y consolidación.

Así, a modo de conclusiones, presentamos aquellos desafíos que entendemos deben ser abordados de manera prioritaria.

En primer término, debe promoverse el aumento de las declaraciones de aceptación por parte de los Estados miembros de las Naciones Unidas. Curiosamente, entre los Estados que no han ratificado o adherido a este instrumento internacional se incluyen prácticamente todos aquellos en que los niveles de incumplimiento alcanzan cotas bastante elevadas, lo que implica que buen número de vulneraciones sufridas por los niños, niñas y adolescentes quedan fuera del ámbito de actuación del Comité de los Derechos del Niño.

En segundo lugar, este procedimiento no es lo suficientemente conocido por parte de la ciudadanía en general y de las presuntas víctimas, reales o potenciales, en particular. No deja de ser llamativo que no se haya presentado ninguna comunicación en relación a ciertos países que han aceptado someterse a este procedimiento - al menos, el individual-y que incurren en evidentes infracciones de los derechos humanos de niñas, niños y adolescentes, tal y como atestiguan los informes periódicos examinados por el propio Comité de los Derechos del Niño. Por el contrario, las quejas se focalizan con respecto a algunos Estados, particularmente España y Dinamarca, y sobre ciertas temáticas muy específicas, lo que nos lleva a pensar que estas denuncias son auspiciadas por un mismo equipo de juristas. Todo ello parece demostrar que la posibilidad de hacer uso de este mecanismo cuasi-jurisdiccional ha sido escasamente difundida entre la población. Sumado a lo anterior, no puede soslayarse la escasa visibilidad con la que ya de por sí cuenta el Comité de los Derechos del Niño.

78 Comité de los Derechos del Niño (2018). 
En tercer lugar, tratar de buscar la forma de agilizar los procedimientos. El Comité de los Derechos del Niño no funciona de manera permanente, sino que se va reuniendo de forma discontinua, y además tiene otras funciones asignadas. Todo ello se traduce en una ralentización de las investigaciones y en la emisión de los dictámenes. Unir a lo apuntado que, si el número de comunicaciones va en aumento durante los próximos años, y esa parece ser la tendencia a seguir, la capacidad de respuesta del órgano ginebrino será aún más complicada. Está por ver si el establecimiento de los grupos de trabajo y relatores sobre nuevas comunicaciones en el seno del Comité se tornará en una respuesta eficaz a la problemática descrita ${ }^{79}$.

En cuarto lugar, incidir en el cumplimiento de las recomendaciones. El Comité debe mejorar su capacidad de persuasión para lograr que los Estados apliquen en todos los casos sus dictámenes. La solución prevista en el Protocolo (art. 11), de solicitar una respuesta al Estado en el mismo texto del dictamen y fijar un plazo para proporcionarla, seis meses como máximo, y, en su caso, solicitar al Estado información sobre el cumplimiento del dictamen en su siguiente informe periódico, se nos antoja del todo insuficiente. Tal vez sería necesario ahondar en el carácter vinculante de los dictámenes emitidos por el Comité. Es decir, que los Estados se vieran obligados, y no dejarlo a su buena voluntad, a justificar las medidas adoptadas en respuesta a las recomendaciones procedentes del órgano ginebrino, y en caso de no hacerlo, ello fuera considerado como una vulneración de las obligaciones asumidas por el Estado al ratificar el texto de la Convención sobre los Derechos del Niño.

En quinto lugar, mejorar la coordinación entre los diferentes mecanismos de supervisión existentes en el sistema de tratados de derechos humanos de las $\mathrm{Na}-$ ciones Unidas. En algunas ocasiones, un mismo supuesto de hecho puede resultar de interés para más de un comité y, por ende, debería preverse la posibilidad de un trabajo conjunto y sistematizado de dichos órganos. En otras, en cambio, el caso presentado puede no ser competencia del mecanismo cuasi-jurisdiccional ante el que se acude, pero sí de otro. Pues bien, un sistema de remisión inter-comités que actuara de oficio agilizaría y garantizaría que las posibles vulneraciones de derechos fundamentales no quedaran sin ser resueltas.

Por último, se nos antoja del todo imprescindible, clarificar el verdadero valor atribuido a la llamada como "jurisprudencia" generada por las resoluciones

79 Estos mismos problemas ya fueron enfatizados por SMITH (2009), pp. 115-116. 
emitidas por el Comité de los Derechos del Niño, para de esta forma ir configurando un acervo de decisiones y dictámenes que nos ayuden a interpretar de manera adecuada el articulado contenido en la Convención sobre los Derechos del Niño y sus Protocolos facultativos.

\section{BiBLIOGRAFÍA CITADA}

Aguilar Cavallo, Gonzalo y Nogueira Alcalá, Humberto (2016): "El principio favor persona en el derecho internacional y en el derecho interno como regla de interpretación y de preferencia normativa”, en Revista de Derecho Público (Año 2016, Vol. 84), pp. 13-43.

Asamblea General de las Naciones Unidas (2011a): A/HRC/17/36, de 25 de mayo de 2011, Informe del Grupo de Trabajo abierto encargado de estudiar la posibilidad de elaborar un protocolo facultativo de la Convención sobre los Derechos del Niño para establecer un procedimiento de comunicaciones.

(2011b): A/HRC/WG.7/2/4, de 18 de enero de 2011, Propuesta revisada de proyecto de protocolo facultativo preparada por el Presidente-Relator del Grupo de Trabajo abierto sobre un protocolo facultativo de la Convención sobre los Derechos del Niño para establecer un procedimiento de comunicaciones.

(2010a): A/HRC/WG.7/2/3, de 13 de octubre de 2010, Observaciones del Comité de los Derechos del Niño sobre la propuesta de Proyecto de Protocolo facultativo preparada por el Presidente-Relator del Grupo de Trabajo abierto sobre un Protocolo facultativo de la Convención sobre los Derechos del Niño para establecer un procedimiento de comunicaciones.

(2010b): A/HRC/WG.7/2/2, de 4 de octubre de 2010, Propuesta de proyecto de protocolo facultativo preparada por el Presidente-Relator del Grupo de Trabajo abierto sobre un protocolo facultativo de la Convención sobre los Derechos del Niño para establecer un procedimiento de comunicaciones.

(2010c): A/HRC/RES/13/3, de 14 de abril de 2010.

(2010d): A/HRC/13/43, de 21 de enero de 2010, Informe del Grupo de Trabajo abierto encargado de estudiar la posibilidad de elaborar un protocolo facultativo de la Convención sobre los Derechos del Niño para establecer un procedimiento de comunicaciones.

Beco (DE), Gauthier (2013): "The optional protocol to the Convention on the Rights of the Child on a Communications Procedure: good news?", en Human Rights Law Review (Vol. 13, No 2), pp. 367-387. 
Belorgey, Jean Michel (2011): "La Charte Sociale du Conseil de l'Europe et son organe de régulation (1961-2011), le Comité Européen des Droits Sociaux: esquisse d'un bilan", en Revue Trimestrielle des Droits de l'Home (No 88), pp. 787-806.

BEKKER, Gina (2013): "The protection of asylum seekers and refugees within the African regional human rights system", en African Human Rights Law Journal (Vol. 13, No 1), pp. 1-29.

Cardona Llorens, Jorge (2012): "La Convención sobre los Derechos del Niño: significado, alcance y nuevos retos", en Educatio Siglo XXI (Vol. 30, No 2), pp. 47-68.

Carlson, Scoot y Gisvold, Gregory (2003): Practical guide to the International Covenant on Civil and Political Rights (New York, Transnational Publishers). Carmona Luque, María del Rosario (2012): "Las obligaciones derivadas de la Convención sobre los Derechos del Niño hacia los Estados partes: el enfoque en derechos en las políticas de infancia en España”, en Educatio Siglo XXI (Vol. 30, No 2), pp. 69-88.

(2011): La Convención sobre los Derechos del Niño. Instrumento de progresividad en el Derecho Internacional de los Derechos Humanos (Madrid, Dykinson).

COMité de los Derechos del NiÑo (2018): Informe de la investigación relacionada en Chile en virtud del artículo 13 del Protocolo facultativo de la Convención sobre los Derechos del Niño relativo a un procedimiento de comunicaciones, de 1 de junio de 2018 -Documento CRC/C/CHL/INQ/1-.

(2016): Observación General No 20. Sobre la efectividad de los derechos del niño durante la adolescencia, de 6 de diciembre de 2016 -Documento CRC/C/CG/20-.

(2013): Observación General No 14. El derecho del niño a que su interés superior sea una consideración primordial, de 29 de mayo de 2013 -Documento CRC/C/CG/14-.

(2009): Observación General No 12, el derecho del niño a ser escuchado, de 20 de julio de 2009, -CRC/C/CG/12-.

(1999): Informe CRC/C/90, de 7 de diciembre de 1999.

Erdem Türkelli, Gamze, Vandenhole, Wouter y Vandenbogaerde, Arne (2013): "NGO impact on Law-Making: The case of a complaints Procedure under the International Covenant on Economic, Social and Cultural Rights 
and the Convention on the Rights of the Child", en Journal of Human Rights Practice (Vol. 5, No 1), pp. 1-45.

European Court of Human Rights (2019): Practical guide on admissibility criteria, Council of Europe. Disponible en https://www.echr.coe.int/Documents/ Admissibility_guide_ENG.pdf [fecha de consulta: 29 de julio de 2019].

Faúndez Ledesma, Héctor (2007): "El agotamiento de los recursos internos en el sistema interamericano de protección de los derechos humanos”, en Revista IIDH, (No 46), pp. 43-122.

GarCía España, Elisa (2016): "De menores inmigrantes en protección a jóvenes extranjeros en prisión”, en Indret 3/2016. Disponible en: http://www.indret. $\mathrm{com} / \mathrm{pdf} / 1231 . p d f$ [fecha de consulta: 13 de junio de 2019].

Gómez Fernández, Itziar y Montesinos Padilla, Carmen (2013): “Agotamiento de los recursos internos y otras exigencias de admisibilidad”, en Protección Multinivel de Derechos Humanos. Manual, George Rodrigo Bandeira Galindo, René Urueña y Aida Torres Pérez (coordinadores), Red de Derechos Humanos y Educación Superior, pp. 213-240. Disponible en: https://www. upf.edu/dhes-alfa/materiales/docs/PMDH_Manual.pdf [fecha de consulta: 22 de julio de 2019].

GonZÁlez Serrano, Andrés (2010): "La excepción preliminar: Falta de agotamiento de recursos internos ¿Un mecanismo efectivo de defensa estatal?”, en Prolegómenos (Vol. XIII, No 26), pp. 245-265.

GonZÁlez Morales, Felipe (2009): “La Comisión Interamericana de Derechos Humanos: antecedentes, funciones y otros aspectos, en Anuario de Derechos Humanos (No 5), pp. 35-57.

LANGFord, Malcolm y Clark, Sevda (2011): "A complaints procedure for the Convention on the Rights of the Child: Commentary on the second draft", en Norwegian Centre for Human Rights (Oslo, University of Oslo), pp. 1-10.

(2010): "A complaints procedure for the Convention on the Rights of the Child: Commentary on the first draft", en Norwegian Centre for Human Rights (University of Oslo), pp. 1-7.

(2010): "The new kid on the block. A complaints procedure for the Convention on the Rights of the Child", en Nordic Journal of Human Rights (Vol. 28, No 3-4), pp. 371-400.

LASO PÉREZ, Javier (2014): "Instrumento de ratificación del Protocolo facultativo de la Convención sobre los Derechos del Niño relativo a un procedimiento 
de comunicaciones, hecho en Nueva York el 19 de diciembre de 2011", en Ars Iuris Salmanticensis, (Vol. 2), pp. 170-176.

Maravall Buckwalter, Isabel (2018): "El derecho del niño a acogerse a la dispensa del deber de declarar: Reflexiones desde el Derecho Internacional de los Derechos Humanos", en Indret 1/2019. Disponible en: http://www. indret.com/pdf/1444_nuevo.pdf [fecha de consulta: 9 de julio de 2019].

Nogueira Alcalá, Humberto (2017): "La protección convencional de los Derechos de los Niños y los estándares de la Corte IDH sobre medidas especiales de protección por parte de los Estados Partes respecto de los niños, como fundamento para asegurar constitucionalmente los Derechos de los Niños y Adolescentes", en Ius et Praxis (Vol. 23, No 2), pp. 415-462. Ochoa Ruiz, Natalia (2004): Los mecanismos convencionales de protección de los derechos humanos en las Naciones Unidas (Madrid, Civitas).

Paúl DíAz, Álvaro (2014): "La revisión inicial de peticiones por la Comisión Interamericana y la subsidiariedad del sistema de derechos humanos, en Revista de Derecho de la Pontificia Universidad Católica de Valparaíso (Vol. XLIII), pp. 609-639.

PhiLIPs, Charlotte (2013): "Optional Protocol to the Convention on the Rights of the Child on a Communications Procedure", en International Association of Youth and Family Judges and Magistrates, pp. 4-8.

PinTo, Mónica (1997): "El principio pro homine. Criterios de hermenéutica y pautas para la regulación de los derechos humanos", en La aplicación de los tratados sobre derechos humanos por los tribunales locales, Abregu, Martín (coord.) (Buenos Aires, CELS-Editores del Puerto), pp. 163-171.

Ravetllat Ballesté, Isaac (2018): "El defensor de los derechos de las niñas, niños y adolescentes en Argentina. De dónde venimos, para saber hacia dónde vamos", La Ley (No 2000), pp. 1-6.

(2017a): "El defensor de los derechos de la niñez en Chile: hacia un verdadero garante de su interés superior", en Estudios Constitucionales (Vol. 15, No 1), pp. 255-306.

(2017b): "La capacidad de obrar de la persona menor de edad no emancipada a la luz del Libro II del Código Civil de Cataluña (artículos 211-3 y 211-5)", en Indret 3/2017. Disponible en: http://www.indret.com/ pdf/1317.pdf [fecha de consulta: 27 de junio de 2019]. 
Riquelme Cortado, Rosa (2014): "Entrada en vigor de los Protocolos facultativos del Pacto Internacional de Derechos Económicos, Sociales y Culturales y de la Convención sobre los Derechos del Niño relativos a un procedimiento de comunicaciones", en Revista Española de Derecho Internacional (Vol. 6, No 2), pp. 11-48.

SAGÜÉs, Néstor (1998): La interpretación de los derechos humanos en las jurisdicciones nacional e internacional (Buenos Aires, Academia Nacional de Derecho y Ciencias Sociales de Buenos Aires).

Saura EstapÀ, Jaume (2013): "La exigibilidad jurídica de los derechos humanos: especial referencia a los derechos económicos, sociales y culturales (DESC)", en Bonet Pérez, Jordi y Saura Estapà, Jaume (editores): El Derecho Internacional de los Derechos Humanos en periodos de crisis. Estudios desde la perspectiva de su aplicabilidad (Madrid, Marcial Pons), pp. 53-80.

Schmid, Marcus (2009): "Follow-up activities by UN Human Rights Treaty Bodies and special procedures mechanisms of the Human Rights Council. Recent developments", en Alfredsson, Gudmundur y Grimheden, Jonas (editores): International human rights monitoring mechanisms: essays in honour of Jakob T.H. Möller (Leiden, Martinus Nijhoff), pp. 25-34.

SMith, Lucy (2009): “Monitoring CRC”, en Alfredsson, Gudmundur y Grimheden, Jonas (Editores): International human rights monitoring mechanisms: essays in honour of Jakob T.H. Möller (Leiden, Martinus Nijhoff), pp. 109-116.

SMITH, Rhona (2010): “The United Nations Human Rights System”, en Baderin, Mashood y Ssenjonjo, Manisuli (editores): International Human Rights law. Six decades after the UDHR and beyond (Surrey, Ashgate), pp. 215-234.

SSEnjonjo, Manisuli (2010): "Economic, social and cultural rights", en Baderin, Mashood y Ssenjonjo, Manisuli (Editores): International Human Rights law. Six decades after the UDHR and beyond (Surrey, Ashgate), pp. 49-88.

YounG, Katharine (2008): "The minimum core of economic, social and cultural Rights", en Yale Journal of International Law (No 33), pp. 113-177. Zayas (DE), Alfred (2009): "Petitions before the United Nations Treaty Bodies: focus on the Human Rights Committee's Optional protocol”, en Alfredsson, Gudmundur y Grimheden, Jonas (Editores): International human rights monitoring mechanisms: essays in honour of Jakob T.H. Möller (Leiden, Martinus Nijhoff), pp. 35-76. 
JURISPRUDENCIA CITADA

Comité de los Derechos del Niño

\begin{tabular}{ll}
\hline Caso Fecha & Referencia \\
\hline $\begin{array}{l}\text { Comunicación No: } \\
\text { 39/2017, M.B. }\end{array}$ & \\
$\begin{array}{l}\text { c. } 31.5 .2018 \\
\text { España }\end{array}$ & CRC/C/78/D/39/2017 \\
\hline Comunicación No: & \\
18/2017, R.I. c. 25.1.2018 & CRC/C/77/D/18/2017 \\
España & \\
\hline Comunicación No: & \\
10/2017, S.C.S & \\
c. 25.1.2018 & CRC/C/77/D/10/2017 \\
Francia & \\
\hline Comunicación No: & \\
9/2017, M.E.B. & CRC/C/75/D/9/2017 \\
c. 2.6.2017 & \\
España & \\
\hline
\end{tabular}

Comunicación No:

8/2017, Y.M. c. 31.5.2018 CRC/C/78/D/8/2016

Dinamarca

Comunicación No:

8/2016, Y.M. c. 31.5.2018 CRC/C/78/D/8/2016

España

Comunicación No:

7/2016, Z.Y. c. 31.5.2018 CRC/C/78/D/7/2016

Dinamarca

Comunicación No:

5/2016, J.A.B.S.

c. 17.1 .2017

CRC/C/74/D/5/2016

Costa Rica 


\begin{tabular}{ll}
\hline Caso Fecha & Referencia \\
\hline $\begin{array}{l}\text { Comunicación No: } \\
\text { 3/2016, I.A.M. }\end{array}$ & \\
$\begin{array}{l}\text { c. } 25.1 .2018 \\
\text { Dinamarca }\end{array}$ & \\
\hline Comunicación No: & \\
2/2015, A.A.A. & CRC/C/73/D/2/2015 $/ 3 / 2016$ \\
c. 30.9.2016 & \\
España & \\
\hline $\begin{array}{l}\text { Comunicación No: } \\
\text { 1/2014, A.H.A. }\end{array}$ & \\
c. 4.6.2015 & CRC/C/69/D/1/2014 \\
España & \\
\hline
\end{tabular}

Comité de Derechos Humanos

\begin{tabular}{ll}
\hline Caso Fecha & Referencia \\
\hline Comunicación No: & \\
488/1992, Toonen. & CCPR/C/50/D/488/1992 \\
$\begin{array}{l}\text { c. 4.4.994 } \\
\text { Australia }\end{array}$ & \\
\hline Comunicación No: & \\
4/1977, Torres. & CCPR/C/10/D/4/1977 \\
c. 26.1.1978 ff & \\
Uruguay & \\
\hline
\end{tabular}

African Committee on the Rights and Welfare of the Child

\begin{tabular}{ll}
\hline Caso Fecha & Referencia \\
\hline Comunicación No: & \\
002/2009, IHRDA. & $002 /$ Com/002/2009 \\
20.4.2009 & \\
IHRDA vs. Kenya & \\
\hline
\end{tabular}




\section{Corte Interamericana de Derechos Humanos}

Caso Fairén Garbi y Solis Corrales, sentencia de 26 de junio de 1987.

Caso Godinez Cruz, sentencia de 26 de junio de 1987.

Caso Velásquez Rodríguez vs. Honduras, de 26 de junio de 1987.

Opinión Consultiva OC-11/90, de 10 de agosto de 1990.

Caso Loayza Tamayo vs. Perú, de 31 de enero de 1996.

Caso Ivcher Bronstein vs. Perú, sentencia de 6 de febrero de 2001.

Caso Herrera Ulloa vs. Costa Rica, de 2 de julio de 2004.

Caso Myrna Mack Chang vs. Guatemala, sentencia de 25 de noviembre de 2005.

Caso Valle Jaramillo y otros vs. Colombia, sentencia de 27 de noviembre de 2008.

\section{Comisión Interamericana de Derechos Humanos}

Resolución No 18/87, Caso No 9.426, Perú, de 30 de junio de 1987.

Informe No 27/93, Caso No 11.092, Canadá, de 6 de octubre de 1993.

Informe No 59/16, Petición 89-07, de 6 de diciembre de 2016. 